\title{
Identificação e mensuração dos custos ocultos em uma empresa fabricante de turbinas automotivas
}

\section{Mayke Zatta Cavali}

maykecavali@gmail.com

Universidade de Caxias do Sul (UCS), Caxias do Sul, Rio Grande do Sul, Brasil

\section{Nilton De Marchi}

nilton@demarchicontabil.com.br

Universidade de Caxias do Sul (UCS), Caxias do Sul, Rio Grande do Sul, Brasil

\section{Alex Eckert}

aeckert@ucs.b

Universidade de Caxias do Sul (UCS) Caxias do Sul, Rio Grande do Sul, Brasil

\section{Marlei Salete Mecca}

msmecca@ucs.br

Universidade de Caxias do Sul (UCS), Caxias do Sul, Rio Grande do Sul, Brasil

\author{
RESUMO
}

O objetivo da presente pesquisa foi verificar quais fatores e operações poderiam ser apontados e mensurados em uma análise dos Custos Ocultos. Para que o objetivo fosse alcançado, realizou-se um estudo de caso, descritivo e qualitativo, em uma empresa do setor metal mecânico fabricante de turbinas automotivas. Inicialmente, alguns dados referentes à produtividade das máquinas analisadas foram coletados, e posteriormente colocados em planilhas para conseguir quantificar os Custos Ocultos presentes nos processos analisados. Um referencial contemplando teorias sobre contabilidade de custos, gestão, gestão de custos e propriamente sobre os Custos Ocultos, deram base para os assuntos envolvidos no decorrer do trabalho. Com a realização da pesquisa foi possível identificar diversos valores ocultos, que foram elencados e quantificados. Todas as análises feitas foram voltadas para o quanto a empresa deixou de faturar pelo fato de estarem ocorrendo falhas nos processos, e também os valores ocultos que acompanham o Custo dos Produtos Vendidos (CPV). Foram realizadas comparações entre os valores buscando a compreensão acerca do surgimento, do impacto gerado e do destino final dos Custos Ocultos. Dentre os principais achados da pesquisa, verificou-se que os valores que a empresa deixou de faturar nos doze meses estudados representaram um valor expressivo em relação ao faturamento total da empresa.
\end{abstract}

PALAVRAS-CHAVE: Custos ocultos. Gestão de custos. Setor metal mecânico. Produtividade. Turbinas. 


\section{INTRODUÇÃO}

Falar em custos frente a um cenário econômico altamente competitivo, certamente faz parte do dia a dia da maioria das organizações. Dessa forma, surge a figura do profissional de custos para auxiliar os gestores com informações ágeis e confiáveis para as tomadas de decisões. É consenso geral nos meios empresariais que toda a empresa, para sobreviver, tem que ter lucros suficientes, não só para manter suas atividades, mas também para proporcionar um crescimento contínuo.

Nos últimos anos, o aumento da velocidade das mudanças, aliadas com um número expressivo de informações, a concorrência se tornou cada vez mais forte, levando uma inevitável pressão para as empresas. Assim, informações cada vez mais apuradas se tornaram vitais para sobrevivência de qualquer atividade econômica.

Empresas que não estão preparadas para essa forte concorrência mercadológica correm riscos de desapareceram, o que pode ser decorrente de vários fatores, algumas por não estarem com processos bem definidos, outras por serem dependentes de um único cliente. Mas também surge um questionamento: será que a empresa tem uma boa gestão para superar as dificuldades encontradas? $\mathrm{O}$ que a área de custos, principalmente a contabilidade de custos, pode ajudar para que essas empresas se mantenham em atividade?

Mazzoni (2015) destaca que os principais objetivos e soluções da contabilidade de custos, nos últimos anos, tem sido os Custos Ocultos e Invisíveis. Trata-se de um novo conceito de fazer contabilidade de custos. Está se notando a necessidade de trabalhar com outras ferramentas para obter um acervo de informações ainda maior, controlando desde custos fáceis de identificar, até os ocultos, que podem estar trazendo distorções relevantes na apuração dessas informações. O conhecimento de custos já não se trata de um fator diferencial, mas sim de um fator primordial na situação mercadológica atual.

A identificação dos custos nas organizações parece um tema muito comum no meio acadêmico, pois encontra-se todos os anos diversas publicações referentes a esse assunto. Mesmo assim, ele é de extrema importância para os fins empresariais, e não deve ser deixado de estudar, pois consegue vislumbrar muitos aspectos que são desconhecidos dos gestores dos negócios, e que ajudam na administração das empresas.

Diante do contexto apresentado, o presente trabalho tem como objetivo identificar quais fatores e operações podem ser apontados e mensurados em uma análise dos Custos Ocultos em uma empresa gaúcha do setor metal mecânico.

\section{REFERENCIAL TEÓRICO}

\section{CONTABILIDE E GESTÃO DE CUSTOS}

A Contabilidade de Custos nasceu da Contabilidade Financeira, com o surgimento da necessidade de mensuração de valores dos estoques na indústria, tarefa essa que era fácil na era do mercantilismo. Seus princípios derivam dessa 
finalidade primeira, mas com a evolução da área, surgem mais duas funções importantes: controle e decisão. Esses dois novos campos deram nova vida a essa área, que por sua vez, apesar de já terem criado técnicas e métodos específicos, ainda não conseguem explorar todo o seu potencial (MARTINS, 2010).

Até o século XVIII, a Contabilidade atendia quase que em sua totalidade as empresas comerciais, desenvolvidas na Era Mercantilista. Com o surgimento da indústria, tornou-se bastante complexa a avaliação dos estoques dos produtos que existiam na empresa e também aqueles que ela mesma produzia. Essa dificuldade se devia pelo fato de os produtos incorporarem diversos fatores de produção utilizados para a sua obtenção (CREPALDI, 2010).

Segundo Bornia (2010), nas primeiras décadas da Revolução Industrial, a produção era em sua totalidade artesanal. $O$ grande aumento de produtividade devido à mecanização dos processos garantiu uma posição confortável às empresas emergentes. Dessa forma a partir das técnicas de administração científicas de Taylor e da linha de produção de Ford, a lógica de produção capitalista modificou-se, havendo enormes melhorias na produtividade industrial. Para Bruni e Famá (2010), as funções básicas de custos devem buscar atender três razões primárias, quais sejam a Determinação do Lucro, o Controle das Operações e a Tomada de Decisões.

Além do pleno conhecimento e controle dos custos incorridos nos processos, há sempre a preocupação de identificar as possibilidades de melhorias, resultando na identificação e eliminação de desperdícios que oneram o custo da produção, consequentemente reduzindo a lucratividade das empresas (PEREZ JR; OLIVEIRA; COSTA, 2012). Bornia (2010) ressalta, que com a evolução das indústrias, temos hoje um cenário altamente competitivo, com produtos de baixo preço e com qualidade. Assim, o efetivo controle dos processos é condição indispensável para que as empresas possam competir em igualdade de condições com seus concorrentes.

Com palavras de Leone (2012), observa-se que a Contabilidade de Custos pode ser considerada um processador, onde ela recebe as informações, acumulaas de forma organizada, analisa e interpreta, assim gerando informações importantes para diversos níveis gerenciais. Para Cruz (2011), entre as suas principais características está em entender a relação da produção de um bem ou serviço com os recursos consumidos no processo. $O$ entendimento dos custos está diretamente relacionado à compreensão de gestão e da operação dos gastos da empresa, que, por meio de suas atividades, procura espaço para às necessidades da sociedade.

Megliorini (2012) afirma que conhecer os custos, é uma condição essencial para administrar uma empresa, seja ela comercial, industrial ou prestadora de serviços. Independente do porte da empresa, não se pode tratar custos de forma secundária, em um mercado altamente competitivo o conhecimento e a boa administração são fatores determinantes na obtenção do sucesso. Bornia (2010) complementa dizendo que controlar as atividades produtivas é uma condição indispensável para que uma empresa possa competir em igualdade entre as concorrentes, ou seja, se avaliar o desempenho das atividades e intervir rapidamente na correção e na melhoria dos processos, a empresa estará em vantagem frente à competição mais eficiente. 
Para Dubois, Kulpa e Souza (2009), a gestão eficaz dos custos para fins de decisões depende de que se tenha familiaridade com o comportamento dos vários gastos que contemplam a produção da empresa. Em diversas situações na realidade empresarial, os custos se apresentam como mistos, ou seja, não se comportam como estritamente fixos ou estritamente variáveis. Sem um conhecimento aprofundado de como os gastos se comportam durante o tempo, ficarão difíceis e inseguras as tomadas de decisões.

\section{CONCEITOS DE CUSTOS}

Segundo Biasio (2012), o gasto é um sacrifício financeiro o qual a entidade arca para a obtenção de um produto ou serviço. Isso somente torna-se gasto quando realmente há a passagem desse bem ou serviço para a propriedade da empresa, ou seja, no momento em que há o reconhecimento contábil da dívida assumida ou da redução do ativo dado ao pagamento.

Bornia (2010) destaca que gasto é o valor dos insumos que são adquiridos pela empresa, independentemente de terem sido utilizados ou não. Também diz que não pode ser confundido com o desembolso, pois o desembolso significa o ato do pagamento, que poderá acontecer em momento diferente do gasto.

Já um investimento, por sua vez, de acordo com Cruz (2011), significa um gasto associado à manutenção da competitividade da empresa pela aquisição de infraestrutura, tecnologia, capacidade, pesquisa e desenvolvimento. Também pode ser considerado investimento com novas unidades de negócios, entre outros.

Dubois, Kulpa e Souza (2009) falam que uma característica natural das empresas que efetuam os investimentos, é a espera que eles proporcionem retorno para a instituição. No caso das matérias primas, o investimento terá retorno no memento em que vender os produtos acabados que foram fabricados com os materiais adquiridos.

São especificamente chamados de investimentos os sacrifícios feitos para a aquisição de bens ou serviços estocados nas empresas, para a sua baixa ou amortização no momento em que será realizada a venda, do seu consumo, de sua desvalorização ou até mesmo no seu desaparecimento (MARTINS, 2010).

Para Dubois, Kulpa e Souza (2009) e Martins (2010), custo é todo o gasto que representa a aquisição de bens e serviços, utilizados para a produção de outros bens ou serviços. Padoveze (2003) complementa dizendo que de um modo geral, os custos são gastos ligados à área industrial da empresa. Bornia (2010) cita alguns exemplos de custos: materiais, trabalho humano, energia elétrica, máquinas e equipamentos, entre outros.

Do ponto de vista econômico, o custo pode ser entendido como qualquer aplicação de recursos, de diferentes formas e expressa em seu valor monetário, para a produção ou distribuição de mercadorias ou prestação de serviços, até o ponto em que se possa receber o preço convencionado (BIASIO, 2012).

Já as despesas são confrontadas com a Contabilidade diretamente com o resultado do período e não devem ser ativadas nos estoques. Podem ser atribuídas aos produtos como forma de análise de gastos e lucratividade individual de um portfólio de produtos ou serviços prestados. Dessa forma ao 
alocar essa despesa aos produtos ou serviços, se trata de um sistema de custos plenos ou integrais (BRUNI; FAMÁ, 2010).

Segundo Padoveze (2003), despesas são gastos necessários para vender e distribuir os produtos, de modo geral podem ser classificados como gastos ligados às áreas comerciais e administrativas. Enquanto o custo é um gasto para conseguir o produto, a despesa é um gasto para vender esse produto.

O desembolso, por sua vez, segundo Martins (2010) e Biasio (2012), significa o pagamento resultante da aquisição do bem ou do serviço realizado, e que poderá ocorrer antes, durante ou depois da entrada da utilidade comprada. Bornia (2010), exemplifica desembolso: se for efetuada uma compra de material com 60 dias de prazo para pagamento, imediatamente ocorrerá o gasto, mas o efetivo desembolso será dois meses depois.

As perdas, por sua vez, são fatos ocorridos em situações excepcionais, ocorrem fora da normalidade das operações da organização. São considerados não operacionais e não devem fazer parte dos custos de produção (PADOVEZE, 2003). Megliorini (2012) complementa afirmando que essas perdas fazem parte dos processos de fabricação, sendo possível minimizá-las, porém não se pode evitar. São chamadas de perdas normais e, por isso, integram o custo do produto. Caso exista material excedente que possa ser utilizado na confecção de outro produto, seu consumo não ficará caracterizado, e o custo correspondente não será apropriado ao produto.

Finalmente, o desperdício Dubois, Kulpa e Souza (2009) utilizam na sua literatura o referido termo como sendo um gasto que a empresa apresenta pelo fato de não ocorrer um aproveitamento normal dos recursos. Citam, inclusive, alguns exemplos: uma produtividade menor do que a capacidade de produção considerada normal para a empresa; um vendedor com tempo ocioso após cumprir com suas cotas de vendas, deixando assim de trazer mais benefícios para a empresa.

\section{CLASSIFICAÇÃO E TIPOLOGIAS DE CUSTOS}

Segundo Megliorini (2012) custos fixos, são aqueles que decorrem da manutenção da estrutura produtiva da empresa, independente da quantidade que venha a ser fabricada dentro dos limites da capacidade instalada. Cruz (2011) complementa falando que os custos fixos podem existir mesmo não havendo consumo nenhum de bem ou serviço. Para Bruni e Famá (2010), os custos fixos podem ter dois agrupamentos: Custo Fixo de Capacidade, relativo às instalações da empresa, refletindo a capacidade instalada da empresa, como depreciação e amortização, e Custo Fixo Operacional, relativo à operação das instalações da empresa, como seguro e imposto predial.

Crepaldi (2010) finaliza com um aspecto importante. Ressalta que os custos são fixos dentro de determinada faixa de produção, e em geral não são sempre fixos, pois podem variar com as grandes oscilações no volume de produção. É um custo fixo no total, mas variável nas unidades produzidas e quanto mais produzir, menor será o custo por unidade.

Já os custos variáveis segundo Cruz (2011) são os gastos voltados à produção de um bem ou serviço que variam de acordo com a quantidade produzida, ou 
seja, os valores sofrerão variações conforme a quantidade de produtos ou serviços prestados pela organização. Padoveze (2003) complementa dizendo que tomando como base o volume de vendas ou produção, os custos são aqueles que em cada alteração da quantidade produzida ou vendida, terão uma variação direta com o seu valor.

Já os custos semivariáveis, de acordo com Padoveze (2003), são os custos em que existe variação em relação à quantidade produzida ou vendida, mas não em uma relação direta. Nota-se essa relação que quando aumenta ou diminui o volume de produção, há um aumento ou diminuição dos custos, porém não se nota essa relação diretamente proporcional aos fatos. Já Bruni e Famá (2010) afirmam que os custos semivariáveis não acompanham linearmente a produção, mas sim aos saltos, e mantem-se fixos dentro de certos limites.

Para os custos semifixos, Megliorini (2012) conceitua como elementos de custos classificados como fixos, mas que se alterna em decorrência de mudanças na capacidade de produção instalada. Padoveze (2003), fala que são considerados semifixos aqueles custos que tem dentro de si uma parcela fixa e outra variável. Se não houver nenhuma produção no período, ou venda, a empresa terá que pagar ao menos uma parcela do custo, que é a parte fixa. A partir de um volume de produção ou de venda, aí sim começará ocorrer proporcionalmente o pagamento da parcela variável.

Segundo Crepaldi (2010) e Megliorini (2012), custos diretos são os custos que podem ser apropriados diretamente aos produtos e variam com a quantidade produzida. Cruz (2011) complementa dizendo que esses custos são identificados sem a necessidade da utilização de rateios.

Os principais custos que definem um custo direto são materiais diretos e mão de obra direta. Os materiais diretos são claramente identificados no produto final, pois estão presentes nas estruturas de produção. A mão de obra direta representa o valor pago aos funcionários que estão diretamente ligados a produção do produto final, até a conclusão em condições de venda (PADOVEZE, 2003).

Os custos indiretos, por sua vez, de acordo com Crepaldi (2010) e Cruz (2011), são os gastos voltados à produção de um bem ou serviço que não se pode identificar diretamente ao produto ou no serviço, sendo assim necessária a utilização de rateios para sua efetiva apropriação ao produto ou serviço. Dubois, Kulpa e Souza (2009) classificam os custos indiretos como sendo de difícil mensuração e apropriação do produto elaborado.

\section{MÉTODOS DE CUSTEIO}

De acordo com Crepaldi (2010), o custeio por absorção é um método onde todos os custos de produção são apropriados nos produtos do período. Os custos de produção podem ser apropriados diretamente como é o caso dos materiais diretos e mão de obra direta, ou indiretamente, como é o caso dos custos indiretos de fabricação. Neste método, todos os gastos que participam da elaboração dos produtos fabricados, deverão ser absorvidos por eles. Os gastos que não pertencem aos processos produtivos, como as despesas, são excluídas. 
Para Leone (2012) o próprio nome indica que se está fazendo absorver no custo de cada departamento e de cada produto final os custos gerais por meio das taxas de absorção. Esse critério é amplamente adotado, sendo ainda um procedimento contábil geralmente aceito. Governo, auditores e empresários preferem empregá-lo, por motivações diferentes.

Um dos grandes desafios dos gestores está na correta distribuição e o controle dos custos indiretos por meio de rateios. Nesse contexto o custeio variável se torna um método alternativo para a gestão de custos, não precisando ratear custos para fornecimento de informações (CRUZ, 2011).

Para Dubois, Kulpa e Souza (2009), a grande vantagem do custeio variável é a utilização da Margem de Contribuição $(\mathrm{MgC})$, que é obtida subtraindo-se do preço de venda os custos e despesas variáveis. A Margem de Contribuição é considerada a mais importante ferramenta de auxílio para as tomadas de decisões. Tais decisões podem ser exemplificadas como a identificação do produto mais lucrativo, implantação de nova linha de produção, comprar ou fabricar internamente e assim por diante.

Crepaldi (2010) fala que esse método de custeio não segue nenhum princípio de Contabilidade do regime de competência e confrontação, portanto não é reconhecido para os efeitos legais, mas sendo de grande valia é claro, para fins gerenciais.

\section{CUSTOS OCULTOS}

Como se sabe, há diversos custos que dificilmente são identificados nos relatórios contábeis e que comprometem o desempenho das organizações. A investigação dos Custos Ocultos se tornou uma curiosidade da sociedade. Esses custos quando identificados, estimam valores e agregam novas informações ao conjunto de dados que se tornam fundamentais nas análises gerenciais, pois influenciam diretamente às perspectivas administrativa, planejamento, controle e de investimentos (FREITAS; SEVERIANO FILHO, 2007).

O método dos Custos Ocultos visa destacar a existência do mau funcionamento e os custos tradicionalmente ignorados pela Contabilidade, afetando a eficiência financeira da organização. É necessário identificar em que ponto aumentam os Custos Ocultos no momento de uma opção estratégica, para determinar a sua viabilidade. Portanto esses custos não podem ser esquecidos pela administração nas tomadas de decisões (PARRA-ACOSTA; PENÃ-GONZÁLEZ, 2014).

Krishnan (2006) frisa a importância de entidades empresariais conhecerem e compreenderem a implicação dos Custos e Falhas Ocultas, e seu impacto nos processos de negócios. Informa ainda em entender os métodos de mensuração de custos existentes na organização, e calcular o custo abrangente de fazer negócios, abrindo caminhos para melhoria de processo, compreensão do escopo do trabalho, agilidade e desempenho, intensificação de cliente interno, e focando na melhoria da satisfação do cliente externo principalmente.

A identificação, mensuração e análise dos Custos Ocultos, tem se revelado um dos desafios da contabilidade gerencial. Autores como Femenick (2005), Freitas e Severiano Filho (2007), abordam em seus estudos a existência de Custos 
Ocultos como fruto de disfunções, variações de desempenho, erros, falhas e não qualidade de produtos e processos. Para facilitar a compreensão, apresenta-se, no Quadro 1, diversos tipos de Custos Ocultos.

Quadro 1 - Classificação dos Custos Ocultos

\begin{tabular}{|c|c|c|}
\hline Categoria & Descrição & Exemplos \\
\hline Má gestão & $\begin{array}{c}\text { Ausência de planejamento, } \\
\text { gerando perda de oportunidade } \\
\text { ou sacrifício pelo abandono de } \\
\text { uma ação. São gastos } \\
\text { decorrentes de decisões } \\
\text { baseadas em análises } \\
\text { superficiais, utilização de } \\
\text { sistemas e processos obsoletos, } \\
\text { existência de liderança omissa e } \\
\text { ausente. }\end{array}$ & $\begin{array}{c}\text { Custos com projetos } \\
\text { inacabados; Custos } \\
\text { com desistência de } \\
\text { projetos mal } \\
\text { planejados. }\end{array}$ \\
\hline Não qualidade & $\begin{array}{l}\text { Decorre do refazer, do corrigir, } \\
\text { dos desperdícios dos itens } \\
\text { produzidos. São considerados: } \\
\text { gastos com devoluções, trocas } \\
\text { de produtos defeituosos, } \\
\text { retoques, disposição de refugos. } \\
\text { Resulta da falta de } \\
\text { direcionamento adequado para }\end{array}$ & $\begin{array}{l}\text { Retrabalho em } \\
\text { peças produzidas; } \\
\text { Substituição de } \\
\text { peças ou produtos. }\end{array}$ \\
\hline Rotatividade de pessoas & $\begin{array}{l}\text { os talentos internos e um clima } \\
\text { organizacional ruim. } \\
\text { Compreende gasto da formação, } \\
\text { investimentos efetuados em } \\
\text { pessoal, contratações. }\end{array}$ & $\begin{array}{l}\text { Treinamentos de } \\
\text { novos funcionários, } \\
\text { substitutos. }\end{array}$ \\
\hline Mau controle & $\begin{array}{l}\text { Custos decorrentes do excesso } \\
\text { de informações e dados que não } \\
\text { agregam valor. São gastos } \\
\text { gerados pela desconfiança e } \\
\text { criação de controles em excesso, } \\
\text { inexistência ou falta de } \\
\text { controles. }\end{array}$ & $\begin{array}{l}\text { Controles duplos } \\
\text { feitos por setores } \\
\text { diferentes. }\end{array}$ \\
\hline Acidente de trabalho & $\begin{array}{l}\text { Normalmente decorrente do } \\
\text { não uso de equipamentos de }\end{array}$ & $\begin{array}{l}\text { Custos com } \\
\text { funcionários }\end{array}$ \\
\hline Set-up & $\begin{array}{c}\text { proteção ou de procedimentos } \\
\text { inadequados de segurança para } \\
\text { a execução das atividades. }\end{array}$ & $\begin{array}{l}\text { afastados e } \\
\text { funcionário }\end{array}$ \\
\hline Espera & $\begin{array}{l}\text { Custo do set-up relacionado às } \\
\text { falhas e ao mau uso do tempo } \\
\text { de preparação do processo } \\
\text { produtivo. }\end{array}$ & para reposição. \\
\hline Ociosidade & $\begin{array}{l}\text { Ocasionado por procedimentos } \\
\text { e métodos não integrados às }\end{array}$ & Custo com pessoal \\
\hline Estoque & $\begin{array}{c}\text { dimensões das demandas do } \\
\text { processo produtivo. }\end{array}$ & $\begin{array}{c}\text { parado, tempo extra } \\
\text { para }\end{array}$ \\
\hline Obsolescência & $\begin{array}{l}\text { Refere-se ao não funcionamento } \\
\text { no tempo certo ou da }\end{array}$ & $\begin{array}{l}\text { regulação de } \\
\text { máquinas. }\end{array}$ \\
\hline
\end{tabular}

Fonte: elaborado pelos autores com base em Freitas e Severiano Filho (2007). 
Zaffani (2006) aponta que, embora tenha relacionado diversos tipos de Custos Ocultos, o assunto ainda não se esgota. Ele chama a atenção dos gestores que muitas vezes convivem com essas situações e nada ou pouco fazem para mudar. Observa-se que as causas mais comuns que conduzem as empresas a essa atitude são o gerenciamento permissivo e tolerante com ocorrências que embutem custos não valorizados, a cultura interna construída com base em valores e ética discutíveis, os lucros muito expressivos no passado ou no presente, que podem desenvolver um nível inaceitável de tolerância e acomodação, além de um paternalismo excessivo, comum na pequena/média empresa, dificultando a implantação de uma gestão profissional.

É notório que nos últimos anos passou-se a ter um foco maior com os custos indiretos de fabricação, pois são os custos que dificilmente são precisos e proporcionam um ambiente inseguro quando se fala dos reais custos de produção industrial (FREITAS; SEVERIANO FILHO, 2007). Os Custos Ocultos são difíceis de serem mensurados, e mesmo sabendo de sua existência, não podem ser diretamente alocados aos produtos ou processos, assim terminam sendo superiores ao esperado pela organização (GAMA; SOUZA; SATO, 2009).

Parra-Acosta e Penã-González (2014) falam que o método de Custos Ocultos exige a presença de dois fatores: primeiro, a visão de longo prazo. Em segundo, a existência de gestão social. Não se pode olhar apenas para questões de cunho financeiro, e negligenciar o fator social. Através de uma gestão social bem realizada, já se pode diminuir os Custos Ocultos, já que em muitos casos a falta de motivação, a remuneração justa e habilidades dos trabalhadores impacta na produtividade, o que por sua vez está diretamente ligada aos desempenhos de processos e financeiros da empresa.

Os Custos Ocultos são evidenciados por uma equação que contrapõe o resultado ideal com o desempenho real da empresa (Custo Oculto $=$ Desempenho Real - Desempenho (deal). Por não poderem ser explicitados, exigem uma atenção especial dos administradores, pois dizem respeito ao montante das receitas da empresa. São custos que não representam gastos, mas sim uma perda na capacidade de geração de receitas (FEMENICK, 2005). Com a mesma visão, Cheah, Shahbudin e Taib (2011) afirmam que poderá haver perda de oportunidades de negócios pelo fato do precário gerenciamento dos Custos Ocultos.

\section{METODOLOGIA}

Quanto aos procedimentos técnicos, foi realizado um estudo de caso único, em uma empresa gaúcha fabricante de turbinas automotivas. De acordo com Gil (1999), o estudo de caso é caracterizado por um estudo aprofundado em um, ou poucos objetos, de maneira a permitir o seu conhecimento amplo e detalhado, tarefa essa que se torna praticamente impraticável mediante os outros tipos de delineamentos. Para Godoi, Bandeira-de-Mello e Silva (2006, p.98) "em estudos de caso, o objetivo claro é a condução de uma pesquisa, e os pesquisadores são investigadores-observadores, não participantes".

A pesquisa ainda teve caráter documental nos procedimentos técnicos, que segundo Chinazzo, Mattos e Weber (2009), essa pesquisa se utiliza de materiais que ainda não receberam um tratamento analítico ou interpretativo, podendo 
servir como base de informações para trabalhos científicos, sendo que esse material pode ser proveniente de órgãos, entidades ou empresas. Beuren (2006) afirma que como na maioria das tipologias, a pesquisa documental pode integrar diversas informações em um mesmo estudo, caracterizando um único delineamento para tal.

Em relação aos objetivos da pesquisa, trata-se de um estudo descritivo. Segundo Oliveira (1999), os trabalhos descritivos permitem controlar de forma simultânea um grande número de variáveis, dando ao pesquisador uma visão abrangente do modo como as variáveis estão ocorrendo. É o tipo de estudo mais adequado quando se necessita obter melhor entendimento a respeito de vários fatores e elementos simultâneos. Nesse contexto, Andrade (2002) destaca que a pesquisa descritiva preocupa-se em observar os fatos, registrá-los, analisá-los, classificá-los e interpretá-los, sem qualquer interferência ou manipulação do autor.

Complementando o delineamento da pesquisa quanto aos objetivos, enquadra-se a pesquisa explicativa, que segundo Gil (1999) é o tipo de pesquisa que mais aprofunda o conhecimento da realidade, explicando a razão e o porquê das coisas. Talvez por isso, seja classificado como complexo e delicado.

Já em relação à forma de abordagem do problema, a presente pesquisa é classificada como qualitativa. Para Oliveira (1999) a abordagem qualitativa em seu sentido prioritário, depende consequentemente da natureza do problema, suas causas e seus efeitos e dos materiais que os métodos permitem coletar. $O$ método referido tem uma pretensão de numerar ou medir unidades de forma homogênea. $\mathrm{O}$ autor também destaca que o método qualitativo apresenta-se de forma adequada para entender de causa e efeito os fenômenos, e consequentemente chegar à verdade e razão.

\section{IDENTIFICANDO E MENSURANDO OS CUSTOS OCULTOS: ESTUDO DE CASO}

A empresa objeto do estudo é uma metalúrgica gaúcha, fundada na década de 1960, que inicialmente atuava como uma oficina mecânica especializada em reformas de motores de caminhões movidos a óleo diesel. Na década seguinte, iniciou-se no Brasil a produção de caminhões turbinados. Devido aos grandes benefícios trazidos pelo sistema de turbo, os proprietários de caminhões produzidos antes deste período passaram a solicitar a adaptação deste equipamento em seus veículos.

Com visão empreendedora, o fundador da empresa passou a fazer viagens periódicas ao centro do país para comprar peças e iniciar a montagem dos turbos que eram adaptados aos caminhões. Após algum tempo, a empresa passou a produzir os próprios turbos, com ampliação gradativa de modelos para outras linhas, que hoje abrange, além de veículos automotores, máquinas agrícolas e motores industriais, estacionários e marítimos.

Os dados coletados são do período de maio de 2015 até abril de 2016, completando um acompanhamento retroativo de 12 meses de produção das duas máquinas presentes na célula de usinagem de carcaças compressoras. 


\section{PROCESSOS E MÁQUINAS}

A empresa que serviu de base para estudos, opera com diversas células produtivas de componentes para montagem de um produto final, o turbo. Devido à complexidade de acompanhamento de todos os setores, o presente estudo objetivou a mensuração dos Custos Ocultos de apenas um setor de produção da empresa. Tal setor tem a função de usinagem da chamada carcaça compressora, sendo esse produto considerado como um dos quatro principais componentes do produto final, o turbocompressor.

Estas peças são compostas de alumínio e sua produção é totalmente realizada na outra empresa do grupo, denominada aqui de fundição. Depois de compradas, essas peças são fundidas e enviadas brutas para a empresa objeto do estudo, onde é realizada a usinagem. Seguindo as estratégias traçadas pela direção, que contempla atender o maior número de itens possíveis para continuar na liderança do mercado brasileiro de reposição, manter relações comerciais com mais de 50 países, e também atender um "mix" de produção que contemple mais de 800 aplicações, a parte produtiva da empresa necessita ser extremamente flexível.

Controlar todos os fatores envolvidos no processo produtivo realmente não é fácil. Se produzir poucas unidades, o tempo de set-up é maior que o tempo de produção, gerando um Custo Oculto do não aproveitamento adequado do equipamento, mas mantém menos estoques de componentes indesejáveis. Do contrário, ao se produzir muitas peças, aproveitando o tempo dos set-ups e diminuindo a ociosidade, os estoques acabam inchando, gerando um custo alto de armazenamento.

\section{APRESENTAÇÃO E ANÁLISES DOS DADOS COLETADOS}

O estudo dos Custos Ocultos em uma empresa pode ser considerado uma forma de coletar algumas disfunções nos processos envolvidos em uma organização. Mesmo estando no mesmo espaço, com atividades semelhantes, adotando comportamentos produtivos similares, há sempre a chance de ocorrem falhas alheias à vontade dos envolvidos. Assim percebe-se a importância do comportamento individual, mas também da coletividade para minimizar a presença dos fatores ocultos.

É importante destacar que esses Custos Ocultos mencionados, não significam dinheiro em espécie saindo do caixa. Femenick (2005) fala que Custos Ocultos são vantagens perdidas medidas monetariamente, em comparação a outras alternativas. Por isso, se pode dizer que esses custos, são uma hipótese do que aconteceria se a empresa optasse pela melhor alternativa comparando com o que acontece na realidade da organização.

Em todo esse contexto, foram analisados três fatores ligados diretamente às máquinas referidas, que seriam os set-ups, ociosidade e também as manutenções. Em outro momento, obtiveram-se dados dos estoques das peças produzidas por essa célula. Os lotes de produção em sua maioria são maiores que as demandas, isso se deve pelo fato dos tempos altos de set-up, que muitas vezes os obrigam a isso. 
Todos os dados foram extraídos de um sistema integrado diretamente com a produção das máquinas, onde os operadores fazem os apontamentos das ordens de produção no início e no término do processo. Esses dados ficam arquivados em um servidor, onde podem ser consultados no momento em que se julgue necessário.

Com o auxílio de um Técnico Analista de Processos de Produção, e também com o auxílio da pessoa responsável pelo PPCP (Planejamento, Programação e Controle da Produção), conseguiu-se informações valiosas para a identificação dos Custos Ocultos do processo em estudo. Após a reunião dos diversos dados coletados, os mesmos foram organizados em planilhas, conseguindo-se fazer combinações de números para chegar ao objetivo inicial desse trabalho, a identificação dos Custos Ocultos nos processos produtivos da empresa.

\section{Custos Ocultos de Produção}

Os Custos Ocultos de produção para o processo avaliado consistem no foco de dois pontos, que são os setu-ps e também a ociosidade. Esses fatos foram analisados com dados extraídos do sistema de acompanhamento de produção integrado nas máquinas da empresa, conforme relatados anteriormente.

As informações provenientes das planilhas feitas para a observação dos Custos Ocultos serão confrontadas com o quanto a empresa estaria deixando de ganhar caso conseguisse minimizar os fatores que estão contribuindo para uma ineficiência industrial, que consequentemente reflete no preço que o consumidor estaria pagando, ou seja, o consumidor tem que pagar pela ineficiência fabril que está oculta no produto adquirido.

\section{Análise dos custos ocultos de set-up}

Os set-ups se tratam de um assunto bastante discutido na indústria, pois se sabe que o tempo que se "perde" regulando as máquinas são valiosos minutos de produção que estão sendo afetados diretamente, dificultando o atendimento dos prazos estabelecidos, e o principal de tudo: o faturamento. Os processos de setups na empresa analisada são bastante enxutos, pois embora não sejam quantificados como nesse estudo, se sabe o impacto desses tempos para os custos de produção.

Os custos de set-up podem ser evidenciados nas duas máquinas do setor de produção em questão. A cada troca de código de produção há um set-up, que muitas vezes pode superar o tempo de produção do lote. Esse processo é bastante demorado pelo fato de ocorrer a troca de todo o ferramental, que não pode ser feito com a máquina em funcionamento, pois o magazine que contempla as ferramentas fica em uma galeria interna e não há outra maneira de ser feito. Dependendo do modelo da peça, podem ser usadas até 20 ferramentas para operações de torneamento, fresamento, furação e rosqueamento.

Com a evolução constante do mercado de turbos, os componentes requerem cada vez mais cuidados para sua confecção. Além de toda a troca do ferramental, devem ser feitas uma ou até duas unidades como cobaias (peças para teste), 
verificando medidas e a qualidade da peça, sendo que todo esse tempo é considerado set-up.

A Tabela 1 mostra os tempos médios mensais de set-ups das máquinas em comparação com os tempos produtivos, mostrando o quanto esses tempos de regulagens de máquinas estão interferindo no tempo total de produção.

Tabela 1 - Tempo total dos set-ups com relação ao tempo de produção 36-A

\begin{tabular}{ccccc} 
Mês & $\begin{array}{c}\text { Mempo Total Set- } \\
\text { ups }\end{array}$ & $\begin{array}{c}\text { Tempó de } \\
\text { Produção }\end{array}$ & $\begin{array}{c}\text { Tempo Total } \\
\text { em Horas }\end{array}$ & $\begin{array}{c}\text { \% Set- } \\
\text { ups/Tempo } \\
\text { Total Horas }\end{array}$ \\
\hline mai/15 & 37,6100 & 155,93 & 193,54 & 19,4327 \\
jun/15 & 47,5700 & 117,64 & 165,21 & 28,7937 \\
jul/15 & 45,2800 & 174,23 & 219,51 & 20,6278 \\
ago/15 & 59,4000 & 169,22 & 228,62 & 25,9820 \\
set/15 & 37,7600 & 140,74 & 178,50 & 21,1541 \\
out/15 & 4,4800 & 53,36 & 57,84 & 7,7455 \\
nov/15 & 50,1400 & 143,22 & 193,36 & 25,9309 \\
dez/15 & 30,4700 & 64,37 & 94,84 & 32,1278 \\
jan/16 & 45,6100 & 145,19 & 190,80 & 23,9046 \\
fev/16 & 61,7100 & 154,15 & 215,86 & 28,5880 \\
mar/16 & 40,0400 & 105,41 & 145,45 & 27,5284 \\
abr/16 & 62,2100 & 121,46 & 183,67 & 33,8705 \\
\hline TOTAIS & 522,2800 & 1544,92 & 2067,20 & 24,6405 \\
\hline
\end{tabular}

Fonte: Elaborado pelos autores com base nos dados coletados

Conforme se pode analisar para a máquina 36-A, o tempo total de set-ups, separados pelos meses analisados, representam na média $24,6405 \%$ do tempo total de produção dos lotes. Em comparação com o custo total da produção para esse período que foi de $\mathrm{R} \$ 955.364,79$, o valor do set-up no ano representa o valor de $\mathrm{R} \$ 235.406,66$ para essa máquina em análise.

Com o mesmo conceito, foram realizadas analises para a outra máquina do setor, que está evidenciado na Tabela 2.

Tabela 2 - Tempo total dos set-ups com relação ao tempo de produção 39-A

$\begin{array}{ccccc}\text { Mês } & \begin{array}{c}\text { Mémpo Total Set- } \\ \text { ups }\end{array} & \begin{array}{c}\text { Tempo de } \\ \text { Produção }\end{array} & \begin{array}{c}\text { Tempo Total } \\ \text { em Horas }\end{array} & \begin{array}{c}\text { \% Set- } \\ \text { ups/Tempo } \\ \text { Total Horas }\end{array} \\ \text { mai/15 } & 33,9200 & 224,81 & 258,73 & 13,1102 \\ \text { jun/15 } & 26,2000 & 179,59 & 205,79 & 12,7314 \\ \text { jul/15 } & 49,1200 & 241,60 & 290,72 & 16,8960 \\ \text { ago/15 } & 46,2900 & 227,71 & 274,00 & 16,8942 \\ \text { set/15 } & 42,4000 & 263,71 & 306,11 & 13,8512 \\ \text { out/15 } & 44,3500 & 258,01 & 302,36 & 14,6679 \\ \text { nov/15 } & 99,7200 & 179,62 & 279,34 & 35,6984\end{array}$




\begin{tabular}{ccccc} 
Mês & $\begin{array}{c}\text { Tempo Total Set- } \\
\text { ups }\end{array}$ & $\begin{array}{c}\text { MéquiNA 39-A } \\
\text { Produção }\end{array}$ & $\begin{array}{c}\text { Tempo Total } \\
\text { em Horas }\end{array}$ & $\begin{array}{c}\text { \% Set- } \\
\text { ups/Tempo } \\
\text { Total Horas }\end{array}$ \\
dez/15 & 54,4300 & 96,49 & 150,92 & 36,0655 \\
jan/16 & 69,8900 & 156,57 & 226,46 & 30,8620 \\
fev/16 & 82,9700 & 128,81 & 211,78 & 39,1774 \\
mar/16 & 11,5600 & 0,00 & 11,56 & 100,0000 \\
abr/16 & 0,0000 & 0,00 & 0,00 & 0,0000 \\
\hline TOTAIS & 560,8500 & 1956,92 & 2517,77 & 27,4962 \\
\hline
\end{tabular}

Fonte: Elaborado pelos autores com base nos dados coletados

Para a máquina 39-A, o percentual foi ainda maior, chegando aos $27,4962 \%$, o que representa $\mathrm{R} \$ \mathbf{2 8 4 . 5 1 8 , 0 1}$ sobre um valor total de produção de $\mathrm{R} \$$ 1.034.753,94.

Analisando os dados das tabelas números 1 e 2, pode-se ter noção do valor Oculto dos set-ups presentes nos produtos. "O método de custeio por absorção caracteriza-se por apropriar todos os custos fixos e variáveis aos produtos. Desse modo, os produtos fabricados "absorvem" todos os custos incorridos de um período" (MEGLIORINI, 2011, p. 26). Megliorini (2011) fala exatamente o que acontece na realidade da empresa. Os custos dos set-ups estão sendo carregados para o "estoque" juntamente com os produtos, pois estão todos inseridos no processo, não havendo distinção do que representa um custo efetivo de produção dos valores ocultos.

Nas tabelas 3 e 4, estão abertos os valores dos tempos de set-ups e de produção de um mês isoladamente, para que se possa enxergar item a item o valor em reais desses Custos Ocultos. Seria inviável apresentar todas as tabelas dos meses analisados, pois no decorrer dos 12 meses analisados, foram realizados 207 set-ups na máquina 36-A e 202 set-ups na máquina 39-A, gerando assim um grande número de dados. Então, serão evidenciados os valores do mês de abril de 2016 apenas, e a máquina em análise será o centro de torneamento 36-A.

Na Tabela 3 estão apresentados os valores totais do processo em análise, onde estão separados por modelos de peças, seguindo das quantidades totais de produção e os valores das matérias primas. Após, com base nas horas trabalhadas, foram rateados os valores da mão e obra direta e também dos gastos gerais de fabricação, gerando o valor total gasto com cada modelo usinado. Os valores de mão de obra e dos gastos gerais são números encontrados pelo autor com base nos dados fornecidos pela contabilidade da empresa analisada e também dados encontrados diretamente no sistema gerencial. 
Tabela 3 - Valores totais de produção mês abril 2016 máquina 36-A

\begin{tabular}{|c|c|c|c|c|c|c|c|}
\hline Modelo & $\begin{array}{l}\text { Pçs } \\
\text { Prod. }\end{array}$ & $\begin{array}{l}\text { Total } \\
\text { M.P. }\end{array}$ & $\begin{array}{l}\text { Horas } \\
\text { Trab. }\end{array}$ & $\begin{array}{c}\text { ABRIL/2 } \\
016 \text { - } \\
\text { MÁQUI } \\
\text { NA 36-A } \\
\% \\
\text { Rateios }\end{array}$ & Valor MOD & $\begin{array}{c}\text { Valores } \\
\text { GGF }\end{array}$ & Valor Tota \\
\hline 807374 & 155 & $\begin{array}{c}\mathrm{R} \$ \\
2.285,66\end{array}$ & $\mathrm{R} \$ 17,46$ & 9,5062 & $\mathrm{R} \$ 396,70$ & $\begin{array}{c}\mathrm{R} \\
9.664,19\end{array}$ & $\begin{array}{c}\mathrm{R} \$ \\
12.346,55\end{array}$ \\
\hline 803171 & 264 & $\begin{array}{c}R \$ \\
4.336,94\end{array}$ & $\mathrm{R} \$ 31,70$ & 17,2592 & $\mathrm{R} \$ 720,25$ & $\begin{array}{c}\mathrm{R} \$ \\
17.546,09\end{array}$ & $\begin{array}{c}\mathrm{R} \$ \\
22.603,28\end{array}$ \\
\hline 803212 & 24 & $\begin{array}{c}\mathrm{R} \$ \\
416,70\end{array}$ & $R \$ 2,33$ & 1,2686 & $\mathrm{R} \$ 52,94$ & $\begin{array}{c}\mathrm{R} \$ \\
1.289,67\end{array}$ & $\begin{array}{c}\mathrm{R} \$ \\
1.759,30\end{array}$ \\
\hline 803231 & 190 & $\begin{array}{c}\mathrm{R} \$ \\
3.398,59\end{array}$ & $\mathrm{R} \$ 33,84$ & 18,4243 & $\mathrm{R} \$ \quad 68,87$ & $\begin{array}{c}\mathrm{R} \$ \\
18.730,59\end{array}$ & $\begin{array}{c}\mathrm{R} \$ \\
22.898,05\end{array}$ \\
\hline 804175 & 84 & $\begin{array}{c}\mathrm{R} \$ \\
1.499,11\end{array}$ & $\mathrm{R} \$ 11,35$ & 6,1796 & $\mathrm{R} \$ 257,88$ & $\begin{array}{c}\mathrm{R} \$ \\
6.282,28\end{array}$ & $\begin{array}{c}\mathrm{R} \$ \\
8.039,27\end{array}$ \\
\hline 804147 & 112 & $\begin{array}{c}\mathrm{R} \$ \\
1.754,88\end{array}$ & $\mathrm{R} \$ 11,71$ & 6,3756 & $R \$ 266,06$ & $\begin{array}{c}\mathrm{R} \$ \\
6.481,54\end{array}$ & $\begin{array}{c}\mathrm{R} \$ \\
8.502,48\end{array}$ \\
\hline 803336 & 154 & $\begin{array}{c}\mathrm{R} \$ \\
2.832,34\end{array}$ & $\mathrm{R} \$ 18,48$ & 10,0615 & $\mathrm{R} \$ 419,88$ & $\begin{array}{c}\mathrm{R} \$ \\
10.228,76\end{array}$ & $\begin{array}{c}\mathrm{R} \$ \\
13.480,98\end{array}$ \\
\hline 804186 & 92 & $\begin{array}{c}\mathrm{R} \$ \\
1.676,97\end{array}$ & $\mathrm{R} \$ 22,15$ & 12,0597 & $\mathrm{R} \$ 503,26$ & $\begin{array}{c}\mathrm{R} \$ \\
12.260,12\end{array}$ & $\begin{array}{c}\mathrm{R} \$ \\
14.440,36\end{array}$ \\
\hline 803383 & 38 & $\begin{array}{c}\mathrm{R} \$ \\
1.262,87\end{array}$ & $\mathrm{R} \$ 4,88$ & 2,6569 & $\mathrm{R} \$ 110,88$ & $\begin{array}{c}\mathrm{R} \$ \\
2.701,10\end{array}$ & $\begin{array}{c}\mathrm{R} \$ \\
4.074,85\end{array}$ \\
\hline 803394 & 51 & $\begin{array}{c}\mathrm{R} \$ \\
1.379,11\end{array}$ & $\mathrm{R} \$ 6,27$ & 3,4137 & $\mathrm{R} \$ 142,46$ & $\begin{array}{c}\mathrm{R} \$ \\
3.470,47\end{array}$ & $\begin{array}{c}\mathrm{R} \$ \\
4.992,04\end{array}$ \\
\hline 803391 & 44 & $\begin{array}{c}\mathrm{R} \$ \\
2.726,54\end{array}$ & $\mathrm{R} \$ 11,02$ & 5,9999 & R 250,38 & $\begin{array}{c}\mathrm{R} \$ \\
6.099,62\end{array}$ & $\begin{array}{c}\mathrm{R} \$ \\
9.076,55\end{array}$ \\
\hline 803397 & 106 & $\begin{array}{c}\mathrm{R} \$ \\
4.305,59\end{array}$ & $R \$ 9,01$ & 4,9055 & 4,71 & $\begin{array}{c}\mathrm{R} \$ \\
4.987,08\end{array}$ & $\begin{array}{c}\mathrm{R} \$ \\
9.497,38\end{array}$ \\
\hline 804289 & 18 & $\begin{array}{c}\mathrm{R} \$ \\
731,14\end{array}$ & $R \$ 3,29$ & 1,7913 & $\mathrm{R} \$ \quad 74,75$ & $\begin{array}{c}\mathrm{R} \$ \\
1.821,03\end{array}$ & $\begin{array}{c}R \$ \\
2.626,92\end{array}$ \\
\hline 803649 & 4 & $\begin{array}{c}\mathrm{R} \$ \\
1.565,62\end{array}$ & $\mathrm{R} \$ 0,18$ & 0,0980 & 4,09 & $\begin{array}{c}\mathrm{R} \$ \\
99,63\end{array}$ & $\begin{array}{c}\mathrm{R} \$ \\
1.669,34\end{array}$ \\
\hline TOTAIS & 1336 & $\begin{array}{c}\mathrm{R} \$ \\
30.172,0 \\
7\end{array}$ & $\mathrm{R} \$ 183,67$ & $\begin{array}{c}100,000 \\
0\end{array}$ & $\begin{array}{c}\mathrm{R} \$ \\
4.173,12\end{array}$ & $\begin{array}{c}\mathrm{R} \$ \\
101.662,1 \\
7\end{array}$ & $\begin{array}{c}\mathrm{R} \$ \\
36.007,36\end{array}$ \\
\hline
\end{tabular}

Fonte: Elaborado pelos autores com base nos dados coletados

Para chegar aos valores totais de mão de obra direta, foram considerados os valores do pagamento efetivo aos colaboradores e também dos encargos sociais. Foram considerados também os dissídios da categoria, que no ano de 2015 para a região de Caxias do Sul, onde São Marcos está enquadrado, representou 9,25\%, conforme dados do site do Sindicato dos Trabalhadores Metalúrgicos de Caxias do Sul e Região.

Os valores totais dos gastos gerais de fabricação foram encontrados a partir de valores das depreciações das máquinas, a qual é linear e deprecia $10 \%$ ao ano. Também foram considerados os valores de materiais de uso e consumo, sendo que foram encontrados os valores totais do referido centro de custos, onde estão inseridas as duas máquinas. Posteriormente, esses valores foram rateados conforme as horas de trabalho de cada uma. 
Para encontrar o valor de consumo de energia de cada máquina, foram analisados dados de consumo por hora dos equipamentos, que representa um valor de $110 \mathrm{KW} / \mathrm{h}$ (informação retirada dos manuais das máquinas). Os números totais de consumos foram multiplicados pelas horas trabalhadas e também pelo valor do $\mathrm{KW} / \mathrm{h}$. Esse valor pode não estar em total conformidade com o consumo real, mas como não se disponibiliza um medidor de energia para cada máquina, essa forma pode dar uma noção aproximada de consumo. Os últimos valores agregados aos gastos gerais foram os valores de manutenção de cada máquina, todos eles divididos por mês.

Na sequência, a Tabela 4 evidencia os valores unitários dos custos incorridos nos processos em análise, sendo eles os custos de matéria prima, mão de obra e gastos gerais de fabricação. Serão distribuídos na tabela de forma que se possam enxergar os Custos Ocultos de produção para cada unidade usinada. Os valores desses Custos Ocultos estão à direita na tabela.

Tabela 4 - Distribuição dos valores unitários de produção e dos Custos Ocultos

\begin{tabular}{|c|c|c|c|c|c|c|c|c|}
\hline Modelo & $\begin{array}{l}\text { Pçs } \\
\text { Prod. }\end{array}$ & $\begin{array}{l}\text { Custo } \\
\text { M.P. } \\
\text { Unit. }\end{array}$ & $\begin{array}{l}\text { Valor } \\
\text { MOD } \\
\text { Unit. }\end{array}$ & $\begin{array}{c}\text { ABRIL/2 } \\
016 \text { - } \\
\text { MÁQUI } \\
\text { NA 36-A } \\
\text { Valor } \\
\text { GGF } \\
\text { Unit. }\end{array}$ & Tota & al Unit. & $\%$ Ocultos & $\begin{array}{l}\text { R\$ Oculto } \\
\text { Unit. }\end{array}$ \\
\hline 807374 & 155 & $\begin{array}{c}R \$ \\
14,75\end{array}$ & $\begin{array}{c}\mathrm{R} \$ \\
2,56\end{array}$ & $\begin{array}{c}\mathrm{R} \$ \\
62,35\end{array}$ & $\mathrm{R} \$$ & 79,66 & 25,2577 & $\begin{array}{c}\mathrm{R \$} \\
20,12\end{array}$ \\
\hline 803171 & 264 & $\begin{array}{c}\mathrm{R} \$ \\
16,43\end{array}$ & $\begin{array}{c}\mathrm{R} \$ \\
2,73\end{array}$ & $\begin{array}{c}\mathrm{R} \$ \\
66,46\end{array}$ & $\mathrm{R} \$$ & 85,62 & 26,5300 & $\begin{array}{c}\mathrm{R} \$ \\
22,71\end{array}$ \\
\hline 803212 & 24 & $\begin{array}{c}\mathrm{R} \$ \\
17,36\end{array}$ & $\begin{array}{r}\mathrm{R} \$ \\
2,21\end{array}$ & $\begin{array}{c}\mathrm{R} \$ \\
53,74\end{array}$ & $\mathrm{R} \$$ & 73,30 & 10,7296 & $\begin{array}{r}\mathrm{R} \$ \\
7,87\end{array}$ \\
\hline 803231 & 190 & $\begin{array}{c}R \$ \\
17,89\end{array}$ & $\begin{array}{r}R \$ \\
4,05\end{array}$ & $\begin{array}{c}\mathrm{R} \$ \\
98,58\end{array}$ & $\mathrm{R} \$$ & 0,52 & 34,1312 & $\begin{array}{c}R \$ \\
41,13\end{array}$ \\
\hline 804175 & 84 & $\begin{array}{c}R \$ \\
17,85\end{array}$ & $\begin{array}{r}R \$ \\
3,07\end{array}$ & $\begin{array}{c}R \$ \\
74,79\end{array}$ & $\mathrm{R} \$$ & 95,71 & 36,7401 & $\begin{array}{c}\mathrm{R} \$ \\
35,16\end{array}$ \\
\hline 804147 & 112 & $\begin{array}{c}\mathrm{R} \$ \\
15,67\end{array}$ & $\begin{array}{c}\mathrm{R} \$ \\
2,38\end{array}$ & $\begin{array}{c}\mathrm{R} \$ \\
57,87\end{array}$ & $\mathrm{R} \$$ & 75,92 & 19,0436 & $\begin{array}{c}\mathrm{R} \$ \\
14,46\end{array}$ \\
\hline 803336 & 154 & $\begin{array}{c}\mathrm{R} \$ \\
18,39\end{array}$ & $\begin{array}{r}\mathrm{R} \$ \\
2,73\end{array}$ & $\begin{array}{c}R \$ \\
66,42\end{array}$ & $\mathrm{R} \$$ & 87,54 & 12,2294 & $\begin{array}{c}\mathrm{R} \$ \\
10,71\end{array}$ \\
\hline 804186 & 92 & $\begin{array}{c}R \$ \\
18,23\end{array}$ & $\begin{array}{r}\mathrm{R} \$ \\
5,47\end{array}$ & $\begin{array}{c}\mathrm{R} \$ \\
133,26\end{array}$ & $\mathrm{R} \$$ & 6,96 & 53,3634 & $\begin{array}{c}\mathrm{R} \$ \\
83,76\end{array}$ \\
\hline 803383 & 38 & $\begin{array}{c}R \$ \\
33,23\end{array}$ & $\begin{array}{c}\mathrm{R} \$ \\
2,92\end{array}$ & $\begin{array}{c}\mathrm{R} \$ \\
71,08\end{array}$ & $\mathrm{R} \$$ & 7,23 & 88,5246 & $\begin{array}{c}\mathrm{R} \$ \\
94,93\end{array}$ \\
\hline 803394 & 51 & $\begin{array}{c}\mathrm{R} \$ \\
27,04\end{array}$ & $\begin{array}{c}\mathrm{R} \$ \\
2,79\end{array}$ & $\begin{array}{c}\mathrm{R} \$ \\
68,05\end{array}$ & $\mathrm{R} \$$ & 97,88 & 48,4848 & $\begin{array}{c}\mathrm{R} \$ \\
47,46\end{array}$ \\
\hline 803391 & 44 & $\begin{array}{c}\mathrm{R} \$ \\
61,97\end{array}$ & $\begin{array}{r}\mathrm{R} \$ \\
5,69\end{array}$ & $\begin{array}{c}\mathrm{R} \$ \\
138,63\end{array}$ & $\mathrm{R} \$ 2$ & 206,29 & 63,3394 & $\begin{array}{c}\mathrm{R} \$ \\
130,66\end{array}$ \\
\hline 803397 & 106 & $\begin{array}{c}R \$ \\
40,62\end{array}$ & $\begin{array}{r}\mathrm{R} \$ \\
1,93\end{array}$ & $\begin{array}{c}\mathrm{R} \$ \\
47,05\end{array}$ & $\mathrm{R} \$$ & 89,60 & 0,0000 & $\begin{array}{c}\mathrm{R} \$ \\
-\end{array}$ \\
\hline 804289 & 18 & $\begin{array}{c}R \$ \\
40,62\end{array}$ & $\begin{array}{r}\mathrm{R} \$ \\
4,15\end{array}$ & $\begin{array}{c}\mathrm{R} \$ \\
101,17\end{array}$ & $\mathrm{R} \$ 1$ & 145,94 & 84,1945 & $\begin{array}{c}\mathrm{R} \$ \\
122,87\end{array}$ \\
\hline 803649 & 4 & $\begin{array}{c}\mathrm{R} \$ \\
391,41\end{array}$ & $\begin{array}{r}\mathrm{R} \$ \\
1,02\end{array}$ & $\begin{array}{c}\mathrm{R} \$ \\
24,91\end{array}$ & $R \$ C$ & 417,34 & 0,0000 & $\begin{array}{c}\mathrm{R} \$ \\
-\end{array}$ \\
\hline
\end{tabular}

Fonte: Elaborado pelos autores com base nos dados coletados 
Com os dados ilustrados na Tabela 4, pode-se ter o valor exato dos valores dos Custos Ocultos de cada unidade produzida. Nota-se também quatro códigos em que os percentuais ocultos ultrapassam os 50\% (804186, 803383, 803391 e 804289 ), isso significa que o tempo de set-up foi superior ao tempo de produção do lote, sendo assim mais relevantes os Custos Ocultos do que os custos de produção efetivamente. Assim como para o mês em análise foram evidenciados dois modelos que não tiveram set-ups, ou seja, os custos dos produtos são todos provenientes da produção das peças, não tendo incidência de valores ocultos para esses casos.

As carcaças compressoras (peças em análise), não são vendidas separadamente, elas são componentes de um produto final. Então para fazer a estimativa de valores ocultos que os clientes pagam nesse componente, solicitouse a engenharia de produtos os valores de venda de cada um desses modelos analisados. Os dados foram tirados do sistema gerencial, que foi alimentado com alguns estudos de custos da empresa.

Se houvesse a venda de todos os componentes usinados na máquina 36-A no período analisado, que contemplam 12 meses chegaria a um valor bruto de vendas de $\mathrm{R} \$ 1$ 1.699.441,43, assim o percentual de Custos Ocultos para essa base de vendas significa $13,8520 \%$, ou seja, o Custo Oculto do processo continua o mesmo e tem um valor de $\mathrm{R} \$ \mathbf{2 3 5 . 4 0 6 , 6 6}$, que aplicados ao valor das vendas, gera o percentual citado. Já para a máquina 39-A, o percentual seria de $16,5720 \%$, referente a uma receita de venda total de $\mathrm{R} \$ 1.716 .861,24$ e com um Custo Oculto de produção de $\mathrm{R} \$ 284.518,01$.

Objetivando realizar uma análise direta desses valores apresentados até o momento, a Tabela 5 evidencia o total dos valores gerais relacionados à produção, e também os valores encontrados nas estimativas de vendas.

Tabela 5 - Valores totais de produção: set-ups e vendas

\begin{tabular}{|c|c|c|c|c|}
\hline & \multicolumn{2}{|c|}{ MÁQUINA 36-A } & \multicolumn{2}{|c|}{ MÁQUINA 39-A } \\
\hline CUSTO TOTAL DE PRODUÇÃO & $\mathrm{R} \$$ & $955.364,79$ & $\mathrm{R} \$$ & $1.034 .753,94$ \\
\hline CUSTO TOTAL DOS SET-UPS (OCULTOS) & $\mathrm{R} \$$ & $235.406,66$ & $\mathrm{R} \$$ & $284.518,01$ \\
\hline VALOR TOTAL DE VENDAS (ESTIMATIVA) & $\mathrm{R} \$$ & $1.699 .441,43$ & $\mathrm{R} \$$ & $1.716 .861,24$ \\
\hline PERCENTUAL OCULTO SOBRE AS VENDAS & & $13,8520 \%$ & & $16,5720 \%$ \\
\hline
\end{tabular}

Fonte: Elaborado pelos autores com base nos dados coletados

Quando se trata em set-ups para a indústria analisada, pode-se observar que os números são relevantes. Sabe-se que o processo não é tão simples e por isso os tempos para essa atividade ainda são grandes, gerando um valor oculto representativo para o custo do produto.

\section{Análise dos custos ocultos da ociosidade}

As análises dos Custos Ocultos para os processos produtivos da empresa foram divididas em set-up e também em ociosidade. Nessa etapa serão abordados fatos específicos de ociosidade, que com palavras de Freitas e Severiano Filho (2007) pode ser identificado como falhas no funcionamento do tempo certo e determinado do processo produtivo. 
As análises foram feitas com base nos meses de maio de 2015 até abril de 2016. Os dados foram todos retirados do sistema operacional da empresa com auxílio do sistema integrado diretamente com a produção das máquinas, onde os operadores alimentam o sistema conforme necessidade da produção.

Se tratando de duas das principais máquinas da empresa, onde o valor hora máquina é alto e o investimento representou grandes valores também, é de grande valia um estudo mais aprofundado para analisar esses lapsos que vem ocorrendo com frequência. É sabido que embora os processos sejam conhecidos há anos, ainda se buscam aperfeiçoamentos.

Pelo fato de estarem acontecendo falhas nos processos, ocasionando paradas inesperadas de produção, os Custos Ocultos são frutos da perda no processo industrial. Assim, para que se pudesse chegar aos valores da ociosidade da empresa, primeiramente foram encontrados os valores da ineficiência industrial (I.Ind.), os "lapsos de falhas", que foram calculados com base na seguinte fórmula:

I.Ind. = Tempo parado por dia em horas

Horas máquina disponíveis dia

Essa fórmula resulta em um percentual que após ser encontrado, será multiplicado com outros fatores envolvidos, os quais serão explanados na sequência. Primeiramente, na tabela 6 , estão evidenciados todos os percentuais de ineficiência industrial encontradas nas duas máquinas presentes na célula de produção. Os números estão separados mês a mês e também com a distinção das máquinas. Nessa mesma tabela, podem-se encontrar todas as horas de ociosidade dos meses analisados individualmente.

A sistemática de cálculos usados nesse trabalho para encontrar os valores ocultos da ociosidade das máquinas estudadas foi baseada em um estudo de Custos Ocultos realizado por Freitas, Almeida e Costa (2008).

Tabela 6 - Horas ociosas mês, dia e percentual de ineficiência industrial 36-A

$\begin{array}{cccc}\text { Idade } & \begin{array}{c}\text { MÁQUINA 36-A } \\ \text { Ociosidade em Horas Mês }\end{array} & \begin{array}{c}\text { Ociosidade em } \\ \text { Dias Mês }\end{array} & \begin{array}{c}\text { \% Ineficiência } \\ \text { Industrial }\end{array} \\ \text { mai/15 } & 49,6520 & 2,4826 & 12,90 \\ \text { jun/15 } & 109,0110 & 5,4506 & 28,31 \\ \text { ago/15 } & 69,4820 & 3,0210 & 15,69 \\ \text { set/15 } & 36,9710 & 1,7605 & 9,15 \\ \text { out/15 } & 54,4680 & 2,5937 & 13,47 \\ \text { nov/15 } & 150,1480 & 7,1499 & 37,14 \\ \text { dez/15 } & 46,4970 & 2,3249 & 12,08 \\ \text { jan/16 } & 216,6420 & 15,4744 & 80,39 \\ \text { fev/16 } & 54,7090 & 2,7355 & 14,21 \\ \text { mar/16 } & 81,9190 & 3,9009 & 20,26 \\ & 44,8480 & 2,0385 & 10,59\end{array}$




\begin{tabular}{cccc} 
& MÁQUINA 36-A & & \\
Idade & Ociosidade em Horas Mês & $\begin{array}{c}\text { Ociosidade em } \\
\text { Dias Mês }\end{array}$ & $\begin{array}{c}\text { \% Ineficiência } \\
\text { Industrial }\end{array}$ \\
abr/16 & 148,1750 & 10,5839 & 54,98 \\
TOTAIS & 1062,5220 & 59,5164 & \\
\hline
\end{tabular}

Fonte: Elaborado pelos autores com base nos dados coletados

Tabela 7 - Horas ociosas mês, dia e percentual de ineficiência industrial 39-A

\begin{tabular}{cccc} 
& MÁQUINA 36-A & & \\
Idade & Ociosidade em Horas Mês & $\begin{array}{c}\text { Ociosidade em } \\
\text { Dias Mês }\end{array}$ & $\begin{array}{c}\text { \% Ineficiência } \\
\text { Industrial }\end{array}$ \\
jun/15 & 59,023 & 2,9512 & 15,33 \\
jul/15 & 150,314 & 7,5157 & 39,04 \\
ago/15 & 98,88 & 4,2991 & 22,33 \\
set/15 & 59,872 & 2,8510 & 14,81 \\
out/15 & 68,738 & 3,2732 & 17,00 \\
nov/15 & 29,302 & 1,3953 & 7,25 \\
dez/15 & 36,255 & 1,8128 & 9,42 \\
jan/16 & 219,208 & 15,6577 & 81,34 \\
fev/16 & 94,219 & 4,7110 & 24,47 \\
mar/16 & 61,934 & 2,9492 & 15,32 \\
abr/16 & 179,326 & 8,1512 & 42,34 \\
TOTAIS & 75,55 & 5,3964 & 28,03 \\
\hline
\end{tabular}

Fonte: Elaborado pelos autores com base nos dados coletados

Para se chegar aos valores da ociosidade das máquinas em análise, além dos valores da Ineficiência Industrial, foi necessário o conhecimento dos dados explanados no Quadro 2, e após inserir na fórmula de ociosidade.

Quadro 2 - Dados da produção para cálculo da ociosidade

\begin{tabular}{|c|}
\hline DADOS DA PRODUÇÃO \\
\hline Volume Médio da Produção Diária (VMPD) \\
Custo Médio de Produção Unitário (CMPun) \\
Tempo Médio Trabalhado (TMT) \\
Ineficiência Industrial (I.Ind) \\
\hline
\end{tabular}

Fonte: Freitas, Almeida e Costa (2008, p. 41)

Quadro 3 - Fórmula da ociosidade

Fórmula Ociosidade $=(\mathrm{VMPd}) \times(\mathrm{CMPun}) \times(\mathrm{TMT}) \times(\mathrm{I} . \mathrm{Ind})$

Fonte: Freitas, Almeida e Costa (2008, p. 41)

O volume médio de produção diária ilustrado no Quadro 2 representa os valores médios de produção diária com base em estatísticas passadas, 
multiplicadas pelo valor de horas trabalhadas em um dia, que para o caso dos estudos analisados, sempre será de 19,25 horas (total de horas produtivas dos dois turnos de trabalho). O custo médio de produção unitário foi estabelecido através dos somatórios dos valores gastos com matérias primas, gastos gerais de fabricação e os valores de mão de obra, divididos pela quantidade de peças produzidas, chegando assim em um valor médio de produção. $O$ tempo médio trabalhado foi considerado como os dias úteis dos meses analisados, e a ineficiência industrial já foi relatado anteriormente a sua origem.

Nas tabelas 8 e 9 são evidenciados todos os valores referentes à ociosidade das máquinas 36-A e 39-A respectivamente, onde estão presentes todos os dados mencionados até o momento, com sua multiplicação realizada, chegando-se aos valores desejados.

Tabela 8 - Valores da ociosidade máquina 36-A

\begin{tabular}{|c|c|c|c|c|c|}
\hline & & & QUINA & & \\
\hline & VMPd & CMPun & TMT & I.Ind \% & Valor Ociosidade \\
\hline mai/15 & 329,18 & 31,12 & 20,00 & 12,8966 & $\mathrm{R} \$ 26.419,25$ \\
\hline jun/15 & 329,18 & 36,27 & 20,00 & 28,3145 & $\mathrm{R} \$ 67.611,88$ \\
\hline jul/15 & 329,18 & 32,56 & 23,00 & 15,6933 & $\mathrm{R} \$ 38.683,06$ \\
\hline ago/15 & 329,18 & 39,29 & 21,00 & 9,1456 & $\mathrm{R} \$ 24.837,81$ \\
\hline set/15 & 329,18 & 42,64 & 21,00 & 13,4738 & $\mathrm{R} \$ 39.718,40$ \\
\hline out/15 & 329,18 & 102,62 & 21,00 & 37,1424 & $\mathrm{R} \$ 263.475,35$ \\
\hline nov/15 & 329,18 & 33,48 & 20,00 & 12,0771 & $\mathrm{R} \$ 26.619,80$ \\
\hline dez/15 & 329,18 & 50,02 & 14,00 & 80,3866 & R185.288,30 \\
\hline jan/16 & 281,24 & 38,17 & 20,00 & 14,2101 & $\mathrm{R} \$ 30.509,98$ \\
\hline fev/16 & 281,24 & 33,07 & 21,00 & 20,2644 & R39.577,17 \\
\hline $\mathrm{mar} / 16$ & 281,24 & 40,69 & 22,00 & 10,5898 & $\mathrm{R} \$ 26.661,21$ \\
\hline$a b r / 16$ & 281,24 & 101,80 & 14,00 & 54,9814 & $\mathrm{R} \$ 220.384,53$ \\
\hline TOTAL & & & & & $\mathrm{R} \$ 989.786,75$ \\
\hline
\end{tabular}

Fonte: Elaborado pelos autores com base nos dados coletados

Tabela 9 - Valores da ociosidade máquina 39-A

\begin{tabular}{cccccc} 
& \multicolumn{5}{c}{ MÁQUINA 36-A } \\
mai/15 & 329,18 & 49,97 & 20,00 & 15,3306 & $R \$ 50.435,33$ \\
jun/15 & 329,18 & 48,65 & 20,00 & 39,0426 & $R \$ 125.043,41$ \\
jul/15 & 329,18 & 43,47 & 23,00 & 22,3331 & $R \$ 73.505,62$ \\
ago/15 & 329,18 & 34,47 & 21,00 & 14,8106 & $R \$ 35.288,24$ \\
set/15 & 329,18 & 36,35 & 21,00 & 17,0038 & $R \$ 42.731,80$ \\
out/15 & 329,18 & 34,93 & 21,00 & 7,2485 & $R \$ 17.502,33$ \\
nov/15 & 329,18 & 41,28 & 20,00 & 9,4169 & $R \$ 25.590,75$ \\
dez/15 & 329,18 & 64,56 & 14,00 & 81,3388 & $R \$ 242.004,58$ \\
jan/16 & 281,24 & 53,27 & 20,00 & 24,4725 & $R \$ 73.329,87$ \\
fev/16 & 281,24 & 58,25 & 21,00 & 15,3207 & $R \$ 52.707,88$
\end{tabular}




\begin{tabular}{cccccc} 
& \multicolumn{5}{c}{ MÁQUINA 36-A } \\
mar/16 & VMPd & CMPun & TMT & I.Ind \% & Valor Ociosidade \\
abr/16 & 281,24 & 0 & 22,00 & 42,3438 & $\mathrm{R} \$$ - \\
\hline TOTAL & 281,24 & 0 & 14,00 & 28,0334 & $\mathrm{R} \$-$ \\
\hline
\end{tabular}

Fonte: Elaborado pelos autores com base nos dados coletados

No somatório dos valores de ociosidade para as duas máquinas, em um período de 12 meses, encontrou-se um valor de R\$ 1.727.926,57. Nota-se também que os valores das médias de produção diária (VMPd) se alteram quando há a mudança do ano em análise, pelo fato que que 2015 obteve uma média de produção no valor de 17,10 peças produzidas por hora, enquanto os quatro primeiros meses de 2016, obtiveram as médias de 14,61 peças por hora de produção. Esses valores representam a capacidade efetiva de produção da empresa no período analisado.

Considerando esses valores de ociosidade, pode-se fazer um comparativo com os custos totais de produção, assim como os realizados com set-ups, para evidenciar os valores da ociosidade junto aos custos do produto, ou seja, verificar o quanto desses valores de ociosidade estão sendo "carregados" para o estoque juntamente com as peças produzidas.

A seguir, na Tabela 10, podem ser analisados os valores médios unitários de ociosidade que estão sendo alocados aos custos dos produtos para as máquinas 36-A. Esses valores são os Custos Ocultos da ociosidade na produção das carcaças compressoras.

Tabela 10 - Valores médios unitários de ociosidade máquina 36-A

\begin{tabular}{|c|c|c|c|}
\hline \multicolumn{4}{|c|}{ Máquina 36-A } \\
\hline & Valores Ociosidade & $\begin{array}{l}\text { Unidades } \\
\text { Produzidas }\end{array}$ & $\begin{array}{c}\text { Valor Unitário } \\
\text { Ociosidade }\end{array}$ \\
\hline mai/15 & $\mathrm{R} \$ 26.419,25$ & 2585 & $\mathrm{R} \$ 10,22$ \\
\hline jun/15 & $\mathrm{R} \$ 67.611,88$ & 1850 & $R \$ 36,55$ \\
\hline jul/15 & $\mathrm{R} \$ 38.683,06$ & 2899 & $\mathrm{R} \$ 13,34$ \\
\hline ago/15 & $\mathrm{R} \$ 24.837,81$ & 2291 & $\mathrm{R} \$ 10,84$ \\
\hline set/15 & $\mathrm{R} \$ 39.718,40$ & 1779 & $\mathrm{R} \$ 22,33$ \\
\hline out/15 & $R \$ 263.475,35$ & 509 & $\mathrm{R} \$ 517,63$ \\
\hline nov/15 & $R \$ 26.619,80$ & 2358 & $\mathrm{R} \$ 11,29$ \\
\hline dez/15 & $R \$ 185.288,30$ & 1043 & $\mathrm{R} \$ 177,65$ \\
\hline jan/16 & $R \$ 30.509,98$ & 2142 & $\mathrm{R} \$ 14,24$ \\
\hline fev/16 & $\mathrm{R} \$ 39.577,17$ & 2363 & $\mathrm{R} \$ 16,75$ \\
\hline $\mathrm{mar} / 16$ & $R \$ 26.661,21$ & 1679 & $R \$ 15,88$ \\
\hline$a b r / 16$ & $R \$ 220.384,53$ & 1336 & $\mathrm{R} \$ 164,96$ \\
\hline
\end{tabular}

Fonte: Elaborado pelos autores com base nos dados coletados

Da mesma forma, na seqüência (Tabela 11), são evidenciados os valores médios da ociosidade alocados aos custos das carcaças compressora usinadas na máquina 39-A. 
Tabela 11 - Valores médios unitários de ociosidade máquina 39-A

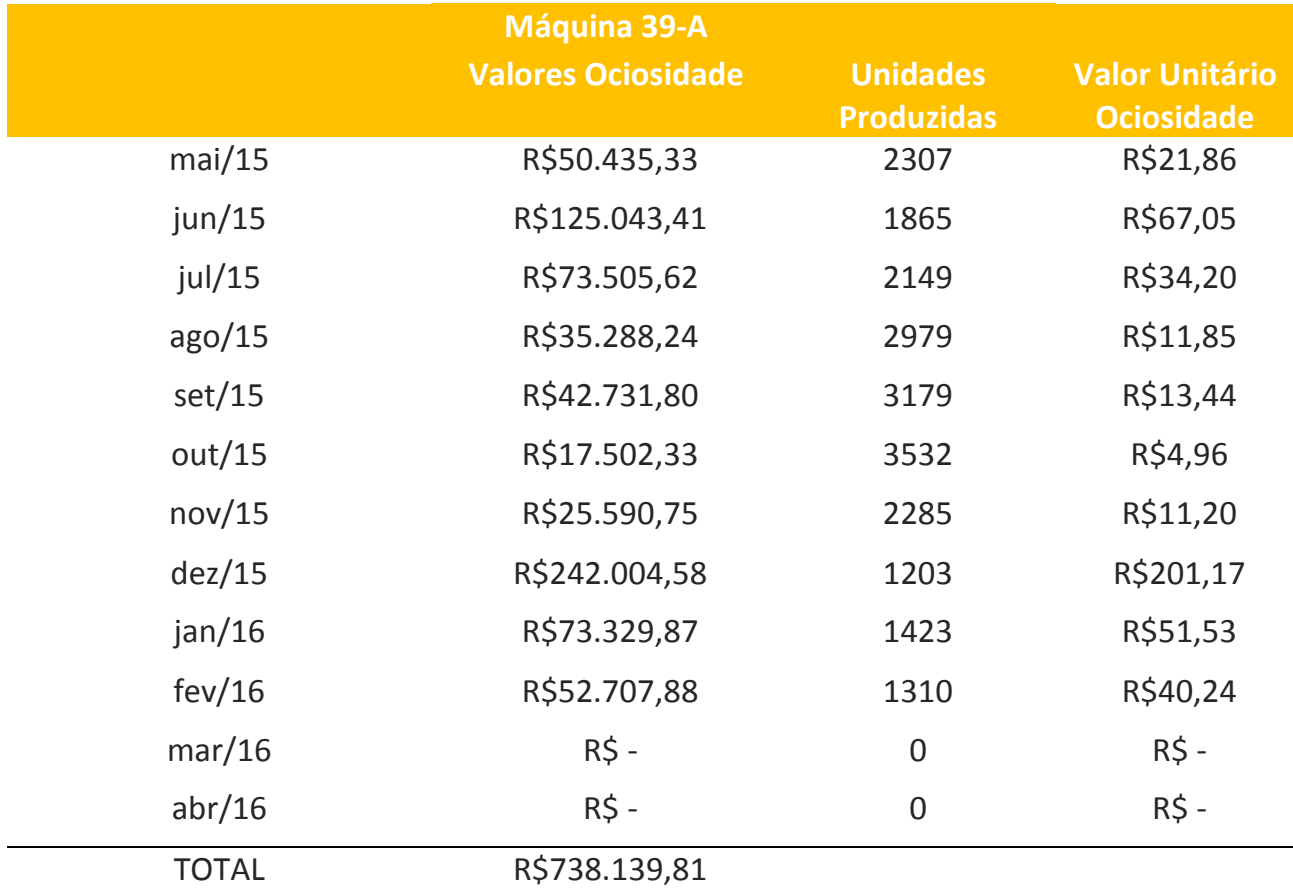

Fonte: Elaborado pelos autores com base nos dados coletados

Com relação aos tempos de produção que são perdidos com essa ociosidade, pode-se fazer uma estimativa de quantas peças deixam de ser produzidas. A Tabela 12 evidencia os valores deixados de faturar, levando em consideração que todas peças produzidas na máquina 36-A fossem comercializadas, enquanto a Tabela 13 evidencia para a máquina 39-A. Esses números de faturamento médio foram extraídos das planilhas que demonstravam os valores de venda de cada componente.

Tabela 12 - Valores de faturamento não realizado máquina 36-A

\begin{tabular}{cccccc} 
& \multicolumn{5}{c}{ MÁQUINA 36-A } \\
Hs Ociosas mês & $\begin{array}{c}\text { Quant. } \\
\text { Peça }\end{array}$ & $\begin{array}{c}\text { Quant. Não } \\
\text { Prod. }\end{array}$ & $\begin{array}{c}\text { Valor } \\
\text { Méd. } \\
\text { Prod. Hs }\end{array}$ & $\begin{array}{c}\text { Valor Não } \\
\text { Faturado }\end{array}$ & $\begin{array}{c}\text { Hs Ociosas } \\
\text { mês }\end{array}$ \\
mai/15 & 49,652 & 17,10 & 849 & 55,3509 & $\mathrm{R} \$ 46.995,63$ \\
jun/15 & 109,011 & 17,10 & 1864 & 64,5199 & $\mathrm{R} \$ 120.270,73$ \\
jul/15 & 69,482 & 17,10 & 1188 & 57,9148 & $\mathrm{R} \$ 68.810,99$ \\
ago/15 & 36,971 & 17,10 & 632 & 69,8864 & $\mathrm{R} \$ 44.182,49$ \\
set/15 & 54,468 & 17,10 & 931 & 75,8562 & $\mathrm{R} \$ 70.652,70$ \\
out/15 & 150,148 & 17,10 & 2568 & 182,5414 & $\mathrm{R} \$ 468.680,59$ \\
nov/15 & 46,497 & 17,10 & 795 & 59,5553 & $\mathrm{R} \$ 47.352,38$ \\
dez/15 & 216,642 & 17,10 & 3705 & 88,9705 & $\mathrm{R} \$ 329.598,30$ \\
jan/16 & 54,709 & 14,61 & 799 & 67,9000 & $\mathrm{R} \$ 54.272,39$ \\
fev/16 & 81,919 & 14,61 & 1197 & 58,8230 & $\mathrm{R} \$ 70.401,46$ \\
mar/16 & 44,848 & 14,61 & 655 & 72,3808 & $\mathrm{R} \$ 47.426,04$ \\
\hline abr/16 & 148,175 & 14,61 & 2165 & 181,0894 & $\mathrm{R} \$ 392.028,89$ \\
\hline
\end{tabular}




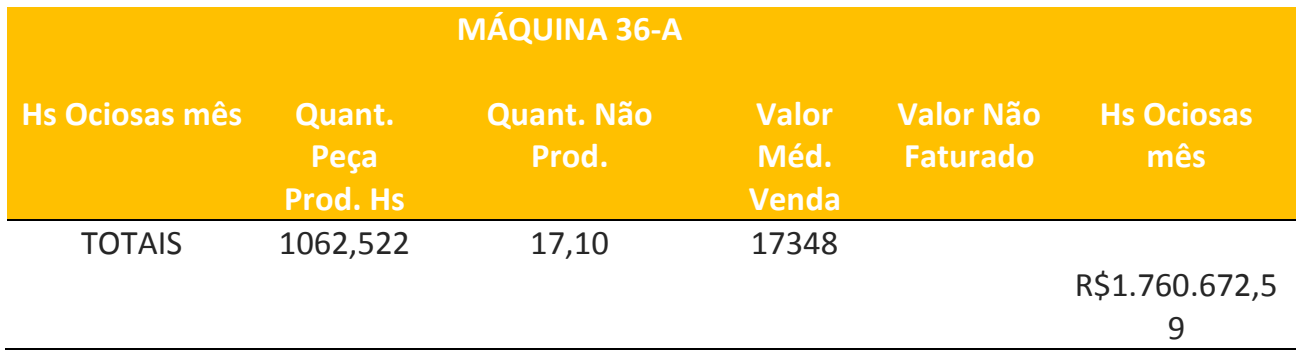

Fonte: Elaborado pelos autores com base nos dados coletados

Tabela 13 - Valores de faturamento não realizado máquina 39-A

\begin{tabular}{|c|c|c|c|c|c|}
\hline \multirow[b]{2}{*}{ Hs Ociosas mês } & \multicolumn{3}{|c|}{ MÁQUINA 39-A } & \multirow[b]{2}{*}{$\begin{array}{l}\text { Valor Não } \\
\text { Faturado }\end{array}$} & \multirow[b]{2}{*}{$\begin{array}{l}\text { Hs Ociosas } \\
\text { mês }\end{array}$} \\
\hline & $\begin{array}{l}\text { Quant. } \\
\text { Peça } \\
\text { Prod. Hs }\end{array}$ & $\begin{array}{c}\text { Quant. Não } \\
\text { Prod. }\end{array}$ & $\begin{array}{l}\text { Valor } \\
\text { Méd. } \\
\text { Venda }\end{array}$ & & \\
\hline mai/15 & 59,023 & 17,10 & 1009 & $\mathrm{R} \$ 88,89$ & $\mathrm{R} \$ 89.716,41$ \\
\hline jun/15 & 150,314 & 17,10 & 2570 & $\mathrm{R} \$ 86,54$ & $\mathrm{R} \$ 222.432,26$ \\
\hline $\mathrm{jul} / 15$ & 98,88 & 17,10 & 1691 & $\mathrm{R} \$ 77,33$ & $\mathrm{R} \$ 130.754,77$ \\
\hline ago/15 & 59,872 & 17,10 & 1024 & $\mathrm{R} \$ 61,31$ & $\mathrm{R} \$ 62.772,15$ \\
\hline set/15 & 68,738 & 17,10 & 1175 & $\mathrm{R} \$ 64,67$ & $\mathrm{R} \$ 76.013,05$ \\
\hline out/15 & 29,302 & 17,10 & 501 & $\mathrm{R} \$ 62,14$ & $\mathrm{R} \$ 31.133,85$ \\
\hline nov/15 & 36,255 & 17,10 & 620 & $\mathrm{R} 73,43$ & $\mathrm{R} \$ 45.521,86$ \\
\hline $\mathrm{dez} / 15$ & 219,208 & 17,10 & 3748 & $R \$ 114,84$ & $\mathrm{R} \$ 430.487,51$ \\
\hline jan/16 & 94,219 & 14,61 & 1377 & $\mathrm{R} \$ 94,76$ & $\mathrm{R} \$ 130.442,14$ \\
\hline $\mathrm{fev} / 16$ & 61,934 & 14,61 & 905 & $R \$ 103,62$ & $R \$ 93.758,91$ \\
\hline $\mathrm{mar} / 16$ & 179,326 & 14,61 & 2620 & $\mathrm{R} \$$ - & $\mathrm{R} \$$ - \\
\hline $\mathrm{abr} / 16$ & 75,55 & 14,61 & 1104 & $R \$$ - & $\mathrm{R} \$-$ \\
\hline TOTAIS & 1132,621 & 17,10 & 18344 & & $\begin{array}{c}\mathrm{R} \$ 1.313 .032,8 \\
9\end{array}$ \\
\hline
\end{tabular}

Fonte: Elaborado pelos autores com base nos dados coletados

Em uma análise geral dos valores de ociosidade, pode-se encontrar desde valores relacionados com a ineficiência industrial até valores que estimam receitas não realizadas, assim, chega-se a um valor total de Custos Ocultos de ociosidade que representam $\mathrm{R} \$ 4.801 .632,05$ para os 12 meses analisados no setor de carcaças compressoras da indústria analisada.

\section{Análise dos Custos Ocultos da Manutenção}

A manutenção visa o perfeito funcionamento das máquinas e equipamentos da empresa, sendo que cada organização adota uma forma específica de realização dessa função. Cada empresa tem suas particularidades de produção, com diferentes elementos e tecnologias próprias, sendo totalmente entendível como cada uma delas realiza essas atividades de reparos.

Quando se relaciona manutenção com Custos Ocultos, se tem uma das funções que mais geram esses custos. $O$ fato da paralização das máquinas para a 
realização das manutenções, tanto preventivas, quanto corretivas, acarretam em não geração de receitas, pois com o equipamento em manutenção, há a interrupção dos processos produtivos, e consequentemente haverá menos produtos e uma menor venda.

Foram analisados dois tipos de manutenção: a Manutenção Preventiva e Manutenção Corretiva, que quando não aplicadas de maneira eficiente acabam contribuindo para a geração de Custos Ocultos. Com palavras de Femenick (2005), o custo de ambas as manutenções é perfeitamente identificável pela Contabilidade, sendo que o Custo Oculto da manutenção é o valor da produção não realizada, quando, por ineficiência da manutenção preventiva, tenha havido a paralização da produção. Os Custos Ocultos da manutenção correspondem ao preço de venda do produto não fabricado.

O ideal seria a realização da manutenção quando houvesse um período de baixa movimentação. Mesmo acontecendo uma pequena baixa nas vendas no término do ano de 2015, foi estabelecida produção máxima até que os estoques de componentes chegassem a um nível desejado pela administração. No começo do ano de 2016, a fábrica estava trabalhando em baixa, pois ainda sentia problemas com vendas, foi onde surgiram maiores números de manutenções preventivas.

Nas tabelas 14 e 15 que estão dispostas na sequência, podem-se analisar os números de manutenções corretivas e preventivas das duas máquinas, onde nota-se que o número manutenções preventivas em maior número nos momentos de baixa produtividade. Também nota-se valores expressivos para manutenções corretivas.

Tabela 14 - Horas preventivas e corretivas realizadas máquina 36-A

\begin{tabular}{ccc} 
Mês & $\begin{array}{c}\text { MíQQUINA 36-A } \\
\text { Manutenções Preventivas em } \\
\text { mai/15 }\end{array}$ & $\begin{array}{c}\text { Manutenções } \\
\text { Corretivas em Horas }\end{array}$ \\
jun/15 & 3,23 & 11,07 \\
jul/15 & 0,00 & 4,85 \\
ago/15 & 0,77 & 0,78 \\
set/15 & 5,95 & 0,00 \\
out/15 & 2,98 & 54,59 \\
nov/15 & 1,28 & 248,98 \\
dez/15 & 12,05 & 0,00 \\
jan/16 & 0,00 & 0,81 \\
fev/16 & 14,09 & 2,53 \\
mar/16 & 3,76 & 0,44 \\
abr/16 & 1,74 & 0,00 \\
\hline TOTAlS & 1,81 & 0,00 \\
\hline
\end{tabular}

Fonte: Elaborado pelos autores com base nos dados coletados

Nota-se no mês de outubro de 2015 um grande número de paradas para manutenção corretiva para a máquina 36-A. Nesse mês em específico, os custos dos produtos produzidos ficaram totalmente distorcidos, pois foram produzidas 
apenas 509 unidades de carcaças devido à quebra do equipamento, ou seja, esse pequeno número de peças acabou carregando em seus custos os valores ocultos, que para esse mês foram grandes.

Para a produção das 509 unidades, incluindo o tempo total dos set-ups, foram gastos 57,84 horas sendo que a máquina ficou 248,98 horas em manutenção, totalizando com essas operações 306,82 horas, logo a produção significou $18,85 \%$ desse tempo total. Considerando que os custos de matériaprima, mão-de-obra e os gastos gerais de fabricação representam um valor de R\$ $52.232,66$, os Custos Ocultos envolvidos no mês de outubro de 2015 totalizam aproximadamente $\mathrm{R} \$ 42.386,80$, assim em uma média geral, pode-se dizer que cada produto está carregando em seus custos um valor oculto médio de R\$ 83,27 .

Percebe-se um grande número de manutenções corretivas para a máquina 39-A nos meses de março e abril de 2016. Essa máquina apresentou um grave problema de manutenção, sendo que para esse caso chegou-se a conclusão de que não foi por falta de manutenções preventivas o acontecimento da quebra. A Tabela 15 evidencia alguns números relativos a esses tempos de manutenções.

Tabela 15 - Horas preventivas e corretivas realizadas máquina 39-A

\begin{tabular}{ccc} 
Mês & $\begin{array}{c}\text { MÁQQUINA 39-A } \\
\text { Manutenções Preventivas em } \\
\text { Horas } 15\end{array}$ & $\begin{array}{c}\text { Manutenções } \\
\text { Corretivas em Horas }\end{array}$ \\
jun/15 & 4,63 & 4,24 \\
jul/15 & 0,00 & 0,00 \\
ago/15 & 0,43 & 0,05 \\
set/15 & 0,00 & 2,03 \\
out/15 & 1,56 & 1,45 \\
nov/15 & 1,08 & 0,41 \\
dez/15 & 0,47 & 0,36 \\
jan/16 & 1,33 & 0,00 \\
fev/16 & 0,48 & 0,04 \\
mar/16 & 4,87 & 6,58 \\
abr/16 & 0,00 & 423,50 \\
\hline TOTAlS & 0,00 & 269,50 \\
\hline
\end{tabular}

Fonte: Elaborado pelos autores com base nos dados coletados

Devido à complexidade do problema, onde as peças de reposição do equipamento quebrado tiveram um prazo longo, acarretou em uma parada de produção de dois meses para essa máquina em específico. Os Custos Ocultos nesse caso são enormes, pois além de não produzir absolutamente nenhuma peça em dois meses, a máquina sofreu depreciação, e esse valor deve ser considerado na análise.

Analisando os meses de março e abril de 2016 nesse momento, pode-se observar que, se considerando as capacidades de produção média dessa máquina dos 6 meses anteriores à quebra que foi 8,76 peças usinadas por hora, e também considerando os tempos médios de produção dos mesmos 6 meses que foram de 
246,16 horas em média (considerando os set-ups), deixariam de serem usinadas 4.313 carcaças. Estabelecendo um preço médio de vendas para esses produtos, o valor das receitas não realizadas (caso todas as unidades fossem comercializadas) chegaria ao valor de $\mathrm{R} \$ 356.877,84$ para os dois meses analisados. O valor médio de vendas foi realizado com base em 10 meses de análises para deixar o cálculo mais perto da realidade possível, esse número representa um valor médio de $\mathrm{R} \$$ 82,75 .

Acrescidos aos valores apresentados no parágrafo anterior deve-se considerar os valores da depreciação da máquina. Essa depreciação é linear, e representa $\mathrm{R} \$ 17.711,92$ por mês, totalizando $\mathrm{R} \$ 35.423,84$ em dois meses. Somando os valores de receitas possíveis não realizadas, e os valores da depreciação, chega-se a um valor de Custos Ocultos de manutenção para uma única máquina em $\mathrm{R} \$ 392.301,68$.

$\mathrm{Na}$ sequência a Tabela 16 evidencia todos os valores de manutenções corretivas e preventivas, analisando quantas unidades poderiam ser produzidas enquanto as máquinas se encontravam em manutenções.

Tabela 16 - Totais de manutenções corretivas e preventivas

\begin{tabular}{|c|c|c|c|c|c|c|}
\hline \multirow[b]{2}{*}{ Hs Corretivas } & \multicolumn{4}{|c|}{$\begin{array}{l}\text { MANUTENÇÕES } \\
\text { CORRETIVAS E } \\
\text { PREVENTIVAS }\end{array}$} & \multirow[b]{2}{*}{$\begin{array}{l}\text { Rec. Não } \\
\text { realizada }\end{array}$} & \multirow[b]{2}{*}{$\begin{array}{c}\text { Hs } \\
\text { Corretivas }\end{array}$} \\
\hline & $\begin{array}{c}\text { Hs } \\
\text { Preventivas }\end{array}$ & Totais & $\begin{array}{l}\text { Méd. } \\
\text { Prod. } \\
\text { Hora }\end{array}$ & $\begin{array}{l}\text { Peças } \\
\text { Não } \\
\text { Prod. }\end{array}$ & & \\
\hline $\begin{array}{c}\text { MÁQUINA 36- } \\
\text { A }\end{array}$ & 324,05 & 47,66 & 371,71 & 14,7801 & 5494 & $\begin{array}{c}\mathrm{R} \$ \\
473.735,51\end{array}$ \\
\hline $\begin{array}{c}\text { MÁQUINA 39- } \\
\text { A }\end{array}$ & 708,15 & 14,85 & 723,00 & 11,3607 & 8214 & $\begin{array}{c}\mathrm{R} \$ \\
679.691,01\end{array}$ \\
\hline TOTAIS & 1032,21 & 62,50 & $\begin{array}{c}1094,7 \\
1\end{array}$ & & 13708 & $\begin{array}{c}\mathrm{R} \$ \\
1.153 .426 \\
52\end{array}$ \\
\hline
\end{tabular}

Fonte: Elaborado pelos autores com base nos dados coletados.

Para a apresentação desses dados colocados na tabela 14, foram estabelecidas médias de produção, ou seja, foram divididos os tempos totais de produção do mês, pelas quantidades de peças produzidas no mesmo mês. Já a receita não realizada, foi projetada com base nos valores médios de venda para as peças no decorrer dos 12 meses analisados.

Assim, chega-se então ao valor total estimado de Custos Ocultos de manutenções das máquinas 36-A e 39-A, que representam $R \$ 1.153 .426,52$ em uma análise realizada de maio de 2015 até abril de 2016 .

\section{Análise dos Custos Ocultos dos Estoques}

Os estoques de uma organização carregam consigo todos os efeitos dos processos produtivos da empresa. Quando vendidos esses estoques, a expressão mais comumente utilizada é de "custo de produtos vendidos", mas pode ser chamada simplesmente de custo de estoque, ou seja, em um estudo dos fatores da produção de uma empresa, consequentemente um dos pontos de conclusão se dará nos estoques, devido a sua importância em uma organização. 
Para o caso da empresa estudada, os estoques são em sua totalidade de componentes do turbocompressor, ou seja, não há unidades prontas estocadas. Essas foram decisões da alta administração na tentativa de atender os clientes de uma forma ágil, pois como a diversidade de itens é grande, estava se tornando impraticável essa sistemática. Muitas vezes o cliente pedia um determinado modelo de turbina que por sua vez teria que ser começado à produção do zero, pois os componentes do item solicitado estavam montados em outros produtos, assim atrasando a entrega.

Atualmente com a sistemática adotada, o cliente coloca o pedido, e em uma média de 8 dias está recebendo seu produto, pois os componentes estão todos prontos no estoque, os quais são solicitados e montados. Antes o prazo que a empresa estabelecia ao cliente para as entregas eram 21 dias, sendo que em sua média eram entregues em 23 dias. Com essa melhora de prazos, notou-se uma grande aceitação dos distribuidores, pois os mesmos sabem que podem confiar em uma entrega média de 8 dias, assim diminuindo seus volumes de estoques, tendo como consequência um maior giro de capitais.

Com palavras de Freitas e Severiano Filho (2007), os estoques provocam altos custos quando mal administrados, gerando custos de manutenção e acondicionamento, levando a empresa empatar seu capital de giro. Esse é o mesmo pensamento dos clientes da empresa estudada. Atualmente, com os prazos médios de entregas girando em torno de 8 dias, não é mais necessário manter em prateleira um grande volume de produtos para atender o mercado, pois se consegue dar um giro de estoques com maior frequência.

Como comentado anteriormente, os estoques são uma consequência da produção, que por sua vez está sendo forçada a ficar mais flexível na empresa. Estão sendo exigidos melhores tempos de set-ups, anulação de paradas produtivas e com manutenções rápidas e eficientes. Isso tudo na tentativa de diminuição da ociosidade, que hoje contempla valores representativos conforme análises anteriores.

Esses Custos Ocultos podem ser encontrados e analisados de diversas formas. Armazenar produto acabado acaba implicando na imobilização do capital e redução de capital investido. Para tanto, pode-se proceder com o cálculo de apuração dos Custos Ocultos achando um valor médio mensal dos estoques de produtos acabados e multiplicá-los por uma taxa de oportunidade de investimentos em títulos de baixo risco, chegando assim a um custo de oportunidade.

Considerando um valor médio de produção dos itens usinados nas duas máquinas do setor analisado, que representa $\mathrm{R} \$ 47,59$ por unidade e levando em consideração um número desejável (estimado pela direção) de 12.000 carcaças compressoras usinadas estocadas, o valor médio dos estoques para esses componentes significam $\mathrm{R} \$ 571.080,00$ mensalmente.

Na Tabela 17 se pode analisar os valores do custo de oportunidade para os meses de janeiro até abril de 2016, e também dos meses de maio até dezembro de 2015, considerando como base o valor médio mensal dos estoques. Existem diversos tipos de investimentos seguros, sendo que para esse trabalho foi escolhido o Tesouro Selic (Sistema Especial de Liquidação e de Custódia), que remunera ao investidor a variação da taxa básica de juros (a taxa Selic) durante o 
período da aplicação. Os dados apresentados foram coletados do site da Secretaria da Receita Federal do Brasil em 21 de maio de 2016.

Tabela 17 - Custo de oportunidade dos estoques com base na Selic

\begin{tabular}{|c|c|c|c|}
\hline \multicolumn{4}{|c|}{ CUSTO DE OPORTUNIDADE } \\
\hline Mês & Custo médio Estoque & $\begin{array}{c}\text { Taxa Selic Mês } \\
\%\end{array}$ & $\begin{array}{c}\text { Custo de } \\
\text { Oportunidade }\end{array}$ \\
\hline mai/15 & $\begin{array}{c}\mathrm{R} \$ \\
57108000\end{array}$ & $0,99 \%$ & $\begin{array}{c}\mathrm{R} \$ \\
5.653 .69\end{array}$ \\
\hline jun/15 & $\begin{array}{c}\mathrm{R} \$ \\
571.080,00\end{array}$ & $1,07 \%$ & $\begin{array}{c}R \$ \\
6.110,56\end{array}$ \\
\hline jul/15 & $\begin{array}{c}\mathrm{R} \$ \\
571.080,00\end{array}$ & $1,18 \%$ & $\begin{array}{c}\mathrm{R} \$ \\
6.738,74\end{array}$ \\
\hline ago/15 & $\begin{array}{c}\mathrm{R} \$ \\
571.080,00\end{array}$ & $1,11 \%$ & $\begin{array}{c}\mathrm{R} \$ \\
6.338,99\end{array}$ \\
\hline set/15 & $\begin{array}{c}\mathrm{R} \$ \\
571.080,00\end{array}$ & $1,11 \%$ & $\begin{array}{c}\mathrm{R} \$ \\
6.338,99\end{array}$ \\
\hline out/15 & $\begin{array}{c}\mathrm{R} \$ \\
571.080,00\end{array}$ & $1,11 \%$ & $\begin{array}{c}\mathrm{R} \$ \\
6.338,99\end{array}$ \\
\hline nov/15 & $\begin{array}{c}\mathrm{R} \$ \\
571.080,00\end{array}$ & $1,06 \%$ & $\begin{array}{c}\mathrm{R} \$ \\
6.053,45\end{array}$ \\
\hline $\mathrm{dez} / 15$ & $\begin{array}{c}\mathrm{R} \$ \\
571.080,00\end{array}$ & $1,16 \%$ & $\begin{array}{c}R \$ \\
6.624,53\end{array}$ \\
\hline jan/16 & $\begin{array}{c}\mathrm{R} \$ \\
571.080,00\end{array}$ & $1,06 \%$ & $\begin{array}{c}\mathrm{R} \$ \\
6.053,45\end{array}$ \\
\hline $\mathrm{fev} / 16$ & $\begin{array}{c}\mathrm{R} \$ \\
571.080,00\end{array}$ & $1,00 \%$ & $\begin{array}{c}\mathrm{R} \$ \\
5.710,80\end{array}$ \\
\hline $\mathrm{mar} / 16$ & $\begin{array}{c}\mathrm{R} \$ \\
571.080,00\end{array}$ & $1,16 \%$ & $\begin{array}{c}R \$ \\
6.624,53\end{array}$ \\
\hline $\mathrm{abr} / 16$ & $\begin{array}{c}\mathrm{R} \$ \\
571.080,00\end{array}$ & $1,06 \%$ & $\begin{array}{c}\mathrm{R} \$ \\
6.053,45\end{array}$ \\
\hline TOTAL & & $0,99 \%$ & $\begin{array}{c}\mathrm{R} \$ \\
74.640,16\end{array}$ \\
\hline
\end{tabular}

Fonte: Elaborado pelos autores com base nos dados pesquisados

Analisando com um número de investimentos em títulos de baixo risco baseados na taxa Selic dos meses analisados, tem-se o valor total do custo de oportunidade em $\mathrm{R} \$ 74.640,16$.

Embora o pavilhão dos estoques da empresa seja próprio, é importante a avaliação da área de estocagem, afinal a empresa tem um capital investido e precisa saber o retorno sobre ele. O prédio onde estão localizados todos os estoques de componentes da empresa contém $370 \mathrm{~m}^{2}$ (metros quadrados), sendo que o espaço designado para as caraças compressoras compreende $75 \mathrm{~m}^{2}$.

O valor médio por $\mathrm{m}^{2}$ de aluguel para um pavilhão como o da empresa em questão é de $R \$ 30,97$, então o valor mensal que seriam gastos com aluguel representa $\mathrm{R} \$ 2.322,75$. Para todos os meses analisados, o valor total seria $\mathrm{R} \$$ $27.873,00$. Os dados de valores médios de alugueis foram coletados do Jornal $O$ Sul, publicado em fevereiro de 2016. A pesquisa foi baseada em 11 cidades, e quem forneceu ao jornal foi a FIPE (Fundação Instituto de Pesquisas Econômicas).

Ainda se pode fazer uma análise do valor gasto com energia elétrica no espaço do estoque. Embora não tenha um medidor de consumo de energia, pode-se estudar o consumo de energia de cada lâmpada por hora, multiplicando 
pela quantidade de horas de trabalho no setor e pelo valor do $\mathrm{KW} / \mathrm{h}$ para os períodos analisados.

São utilizadas 20 lâmpadas LED (do inglês Light Emitting Diode), que significa diodo emissor de luz, com potencia de 60W (Watts), convertendo, isso significa $0,60 \mathrm{KW} / \mathrm{h}$ (Kilowatts Hora). Sendo que as lâmpadas ficam ligadas durante 10 horas diárias, e que cada lâmpada consome $0,60 \mathrm{KW} / \mathrm{h}$, as 20 lâmpadas consomem $12 \mathrm{~kW} / \mathrm{h}$ por dia. Foram trabalhados 238 dias nos períodos analisados, ou seja, o consumo dessas lâmpadas significou um consumo de 2.856 $\mathrm{KW} / \mathrm{h}$. O valor médio da energia por $\mathrm{KW} / \mathrm{h}$ que a empresa pagou durante o período estudado foi de $\mathrm{R} \$ \mathbf{0 , 6 9 0 7}$, totalizando um gasto aproximado de energia de $\mathrm{R} \$ 1.972,64$.

Considerando todos os valores anteriormente citados, para todos os meses analisados o total dos Custos Ocultos dos estoques fica em $\mathrm{R} \$ 104.485,80$.

\section{CONSIDERAÇÕES FINAIS}

Olhando isoladamente para cada processo analisado, percebe-se que nos set-ups em muitas ocasiões o tempo de regulagem das máquinas supera o tempo de produção. Isso gera um grande impacto de custos para as peças usinadas nesse processo.

Caso prevaleça a ideia de manter todos os produtos hoje existentes a disposição dos clientes, o que se sugere é um estudo voltado aos lotes econômicos de produção. Quando programar a produção deve-se observar os tempos de preparação das máquinas em termos de custos, ou seja, verificar qual a quantidade ideal de peças que devem ser produzidas para que seja economicamente viável com tempo de preparação extenso.

Talvez para essa metodologia seja necessária uma mudança de conceito de trabalho de toda uma fábrica, pois atualmente os prazos de entrega médios do produto final estão funcionando na base de 8 dias, tanto para itens de curva $A$, quanto para itens das curvas B e C. Com lotes econômicos de produção talvez seja prudente rever os prazos para as entregas dos itens da curva $C$, pois se pressupõe que esse prazo terá que ser estendido.

Ainda referindo-se aos set-ups, seria importante um trabalho voltado para a diminuição dos tempos de regulagens. Chegar a menos de um dígito conforme a literatura indica seria utopia, mas fazer com que os valores atuais diminuam, acredita-se que é possível. Fazer um trabalho estratégico envolvendo os operadores que fazem set-ups, lhes mostrando o quanto esse tempo impacta na produtividade e na lucratividade da empresa, seria algo interessante. Não basta apenas a direção, gerência e supervisão dos processos entenderem o quanto é significante esses tempos parados, deve-se partir para o coletivo, somente assim há possibilidade de mudanças, e as quebras de paradigmas acontecerão.

Notou-se a presença de tempos ociosos em todos os meses analisados, gerando assim um valor representativo no final dos estudos. Certamente esses valores da ociosidade estão sendo carregados para os estoques, sendo que deveriam ser levados diretamente para as despesas, evitando uma superavaliação destes. 
O que se pode sugerir para essa questão, é uma avaliação dos processos, na tentativa de organizar quantidades exatas de produção, não fazendo com que a máquina fique esperando por peças brutas após o término do lote anterior. São pequenos detalhes que no final das contas podem representar várias unidades não faturadas, conforme estudos feitos no tópico 3.2.1.2 do presente trabalho.

Não seria algo impossível zerar os tempos de ociosidade. Se isso acontecer se ganhará muito em produtividade e consequentemente os valores de Custos Ocultos envolvidos nos estoques seriam diminuídos. Para isso os envolvidos no processo precisam ter conhecimento dessas falhas e colocar planos de ação, certamente bons frutos serão colhidos.

As manutenções carregam consigo grandes números de Custos Ocultos, o que se torna inevitável, pois se a máquina encontra-se em manutenção tanto preventiva, quanto corretiva, obviamente ela não está em operação. Assim, não havendo produção e consequentemente faturamento.

Para essa análise de manutenções deve-se ter a compreensão da importância do acontecimento da manutenção preventiva. Ela deve ser respeitada e realizada conforme planejamentos, mesmo que isso implique em uma pequena parada de produção. Para tanto, o pessoal da manutenção deve executar as tarefas de forma rápida e eficiente, na tentativa de afetar o menor tempo possível de produtividade.

Para as manutenções corretivas se trata de um assunto mais complicado. Infelizmente as máquinas analisadas apresentaram muitas paradas para manutenção corretiva. A máquina 39-A, por exemplo, nos meses de março e abril de 2016 não produziu nenhuma peça pelo fato de estar em manutenção. Houve um fator relevante para esse caso que foi a demora do conserto da peça estragada.

Esse caso é bastante delicado, pois se trata do envolvimento de grandes valores, porém como a empresa tem 4 máquinas idênticas às analisadas, e levando em consideração que o problema apresentado na máquina 39-A já ocorreu em outra máquina, seria conveniente ter uma peça para troca quando o problema aparecer. A peça custa aproximadamente $\mathrm{R} \$ 120.000,00$, mas o custo da máquina parada por dois meses superou esse valor, assim deixando mais um ponto para análise. Obviamente que, se for manter estoque todas as peças de manutenções das máquinas, se trataria de valores muito maiores do que o apresentado anteriormente, mas seria conveniente uma análise aprofundada sobre o assunto.

A última análise dos estudos do presente trabalho foram os estoques de carcaças compressoras usinadas. Esses estoques carregam consigo todos os Custos Ocultos evidenciados nas análises no tópico 3, mas além daqueles, a própria operação de estoque gera Custos Ocultos. Seria conveniente um levantamento de quais itens estão no estoque por mais tempo, deixando o capital investido pela empresa "parado" na prateleira. Esses itens estão tirando o lugar de peças que tem um maior giro de estoques, ou seja, estão apenas empatando dinheiro.

Se forem achadas peças que representam bom volume e que a demanda é pequena, talvez fosse mais viável tirá-las do estoque e aproveita-las como matéria- prima para outros modelos do que deixar sem utilização por anos. 
Deveriam ficar apenas algumas unidades, para atender as demandas futuras, pois se for começar a produção do zero e usinar uma quantidade maior que a demanda apenas para aproveitamento dos tempos de máquina, voltaria aos problemas novamente. Esses valores de peças paradas nos estoques sem utilização poderiam estar aplicados no próprio capital de giro da empresa, ou em títulos de baixo risco, virando um custo de oportunidade.

Felizmente, a empresa, no longo de seus 50 anos, conseguiu obter uma base sólida, e consegue trabalhar com bons estoques sem que isso comprometa o seu capital de giro, mas é sempre importante cuidar dos custos envolvidos com estoques.

\section{CONCLUSÃO}

Como parte final desse estudo, este capítulo visa apresentar algumas considerações ao que já foi escrito e também esclarecer acerca do objetivo da pesquisa. Aqui também estarão dispostas algumas sugestões de melhorias para os processos analisados, assim como propostas para novos estudos complementando o que não foi possível evidenciar nesse trabalho.

O objetivo estabelecido para esse estudo era identificar quais fatores e operações poderiam ser apontadas e mensuradas em uma análise dos Custos Ocultos de uma empresa gaúcha do setor metal mecânico. Encontrou-se Custos Ocultos nos quatro processos analisados, sendo eles todos voltados para o processo de usinagem das carcaças compressoras. Foram analisados os tempos de set-ups, a ociosidade, tempos de manutenções preventivas e corretivas e também foram analisadas as questões de acondicionamento dessas peças produzidas pelo setor mencionado.

Os estudos e análises foram voltadas para os valores que a empresa deixou de faturar nos doze meses estudados, representaram um valor considerável, sendo que foram analisadas apenas duas máquinas do parque fabril da empresa. Entende-se a complexidade envolvida nos trabalhos frente a grande diversidade de produção existente, porém deve-se deixar de lado a hipocrisia e trabalhar para que melhorias aconteçam.

Esse foi um dos pontos chave do trabalho. Auxiliar de alguma forma a diretoria da empresa a enxergar algo que não está em evidência. Com os dados relatados, com os valores levantados e analisados, há sim a possibilidade de ver os processos de forma diferenciada, sempre na busca de maior eficiência na produtividade.

Frente às análises realizadas e também depois das conclusões tiradas, podese dizer que a união de todos os fatores que incluem o aumento da produtividade com a diminuição dos custos de fabricação, traria uma consequência de mais componentes usinados a disposição. Com maior produtividade, haveria a diminuição dos Custos Ocultos, pois isso representa uma fraqueza interna da empresa, que proporciona perdas de rendimento dos processos, e quando reduzidos podem estar possibilitando maiores investimentos para a própria empresa, melhorando resultados financeiros e ainda possibilitando resultados positivos para os clientes. 
Esse trabalho teve a iniciativa de identificar e mensurar os Custos Ocultos dos processos estudados. Com essa base relatada, podem ser explorados estudos voltados para a engenharia de produção, na tentativa de ajustar os processos para a obtenção de melhores tempos de produtividade, sejam eles em modificações de layout, modificações de produção, enfim, mudanças para a diminuição desses fatores ocultos negativos. 


\title{
Identification and Measurement of Hidden Costs in a Brazilian Turbine Manufacturer Company
}

\begin{abstract}
The main objective of this research was to identify which factors and operations could be pointed out and measured in an analysis of Hidden Costs in a metal mechanic company in the state of Rio Grande do Sul (Brazil). Productivity of the analyzed machines were collected, and later placed in spreadsheets to be able to quantify the Hidden Costs present in the analyzed processes. A frame of reference contemplating theories of cost accounting, management, cost management and proper Hidden Costs, provided the basis for the issues involved in the course of the work. With the accomplishment of the research it was possible to identify diverse hidden values. In addition to listing these costs, they were also quantified. All the analyzes made were focused on how much the company failed to invoice due to the fact that process failures are occurring, as well as the hidden values that accompany the cost of products sold. Comparisons were made between the values, always seeking clarity in the facts so that from cost connoisseurs to lay people understand how they arise, what impact they generate and where they will stop the Hidden Costs. The conclusions were based on the analyzes made in the present work, leaving some suggestions of analysis for the studied processes, besides leaving a suggestion for new studies, in order to complement what is explicit in this work.
\end{abstract}

KEYWORDS: Cost Management. Hidden Costs. Mechanical metal sector. Productivity. Turbine. 


\section{REFERÊNCIAS}

ANDRADE, M. M. Como Preparar Trabalhos de Cursos Para Pós Graduação: Noções Práticas. 5 ed. São Paulo: Atlas, 2002.

AUTOMOTIVEBUSINESS. BorgWarner ainda Espera demanda maior por turbos. Disponível em http://www.automotivebusiness.com.br/noticia/23547/borgwarner-aindaespera-demanda-maior-por-turbos. Acesso em 14 maio 2016.

BEUREN, I. M. Como Elaborar Trabalhos Monográficos em Contabilidade: Teoria e Prática. 3 ed. São Paulo: Atlas, 2006.

BIASIO, R. Contabilidade de Custos: Para o Exame de Suficiência do CFC. Coleção Exame de Suficiência do CFC: Bacharel em Ciências Contábeis. São Paulo: Edipro, 2012.

BORNIA, A. C. Análise Gerencial de Custos: Aplicação em empresas Modernas. 5. ed. 3 reimpressão. São Paulo: Atlas, 2010.

BRUNI, A. L.; FAMÁ, R. Gestão de Custos e Formação de Preços: Com Aplicação na Calculadora HP 12C e Excel. Série Finanças na Prática. 2. ed. São Paulo: Atlas, 2010.

CHEAH, S.J.; SHAHBUDIN, A. S.M.; TAIB, F.M. Tracking Hidden Quality Costs in a Manufacturing Copany: An Action Research. International Journal of Quality \& Reliability Management, Vol. 28, n. 4. p. 405-425, 2011. crossref

CHINAZZO, C. L.; MATTOS, P. N.; WEBER, O. J. Instrumentalização Científica. Porto Alegre: Imprensa Livre, 2009.

CREPALDI, S. A. Curso Básico de Contabilidade de Custos. 5. ed. São Paulo: Atlas, 2010.

CRUZ, A. W. Gestão de Custos: Perspectivas e Funcionalidades. Curitiba: Ibpex, 2011.

DUBOIS, A.; KULPA, L.; SOUZA, L. E. Gestão de Custos e Formação de Preços:

Conceitos, Modelos e Instrumentos: Abordagem do Capital de Giro e da Margem de Competitividade. 3. ed. São Paulo: Atlas, 2009. 
FEMENICK, T. R. A Problemática e a solução para os "Custos Invisíveis" e "Custos ocultos". Revista da FARN, Vol 04, n. 1/2, p. 49-61, jul/2004/dez. 2005.

FREITAS, J. B.; SEVERIANO FILHO, C. Apreciação dos Custos Ocultos do Processo Sucroalcooleiro em Uma Usina de Álcool na Paraíba. Revista Gestão Industrial, Vol 03, n. 1, p. 52-63, 2007. crossref

FREITAS, J. B.; ALMEIDA, M. L.; COSTA, I. Custos Ocultos e Agronegócio: Discussões Acerca de Um Caso Observado. Custos e @gronegócio on line, Vol 04, n. 1, p. 26-45, jan/abril 2008.

GAMA, I. S.; SOUZA, M. P.; SATO, S. A.S. Apreciação dos Custos Ocultos na Indústria de Laticínios no Município de Cocoal-Rondônia. XVI Congresso Brasileiro de Custos, Fortaleza, Nov. 2009.

GIL, A. C. Métodos e técnicas de pesquisa social. 5 ed. São Paulo: Atlas, 1999.

GODOI, C. K.; BANDEIRA-DE-MELLO, R.; SILVA, A. B. Pesquisa Qualitativa em Estudos Organizacionais: Paradigmas, Estratégias e Métodos. São Paulo: Saraiva, 2006.

KRISHNAN, S. K. Increasing the Visibility of hidden failure Costs. Measuring Business Excellence. Vol. 10. № 4. P. 77-101, 2006. crossref

LEONE, J. S. G. Custos: Planejamento, Implantação e Controle. 3. ed. 8. Reimpr. São Paulo: Atlas, 2012.

MARTINS, E. Contabilidade de Custos. 10. ed. São Paulo: Atlas, 2010.

MAZZONI, F. Comitê de Economia e Finanças Debate Soluções para Custos, Ocultos e Invisíveis das organizações. www.amcham.com.br. Publicação em: 03/10/2014. Acesso em: 15/09/2015.

MEGLIORINI, E. Custos: Análise e Gestão. 3. Ed. São Paulo: Pearson Prentice Hall, 2012.

OLIVEIRA, S. L. Tratado de Metodologia Científica: Projetos de Pesquisas, TGI, TCC, Monografias, Dissertações e Teses. São Paulo: Pioneira, 1999.

PADOVEZE, C. L. Curso Básico Gerencial de Custos. São Paulo: Pioneira Thomson Learning, 2003. 
PARRA-ACOSTA, J. F.; PENÃ-GONZÁLEZ, Y. C. Lá Teoría de Los Costos-Desempenõs Ocultos: Una Aproximación Teórica. Cuadernos de Contabilidad. Vol 15. N³9. P. 725-743, 2014.

PEREZ JR, J. H.; OLIVEIRA, L. M.; COSTA, R. G. Gestão Estratégica de Custos.

Textos, Casos Práticos e testes com as Respostas. 8. ed. São Paulo: Atlas, 2012.

ZAFFANI, C. A. Cuidado com os custos "invisíveis"!. São Paulo,2006. Disponível em < http://www.clacgraf.com.br/content.php?recid=85>. Acesso em: 21 maio 2016.

CAVALI, M. Z.; MARCHI, N.; ECKERT, A.; MECCA, M. S. Identificação e mensuração dos custos ocultos em uma empresa fabricante de turbinas automotivas. R. Gest. Industr., Ponta Grossa, v. 14, n. 1, p. 199-234, jan./mar. 2018. Disponível em: $<$ https://periodicos.utfpr.edu.br/rgi $>$. Acesso em: XXX.

Correspondência:

Alex Eckert

Rua Francisco Getúlio Vargas, 1130, Caxias do Sul, Rio Grande do Sul, Brasil.

Direito autoral: Este artigo está licenciado sob os termos da Licença Creative Commons-Atribuição 4.0 Internacional. 